\title{
Identifying Occupational and Non-Occupational Factors Affecting the Retention of Health Care Employees in the COVID-19 Pandemic: A Systematic Review Study
}

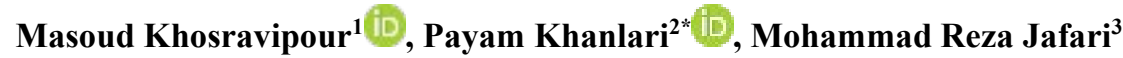

1. M.Sc. Student, Department of Occupational Health Engineering, School of Public Health, Kermanshah University of Medical Sciences, Kermanshah, Iran

2. M.Sc. Student, Department of Ergonomics, School of Public Health, Hamadan University of Medical Sciences, Hamadan, Iran

3. PhD Student, Department of Medicine, School of Medicine, Kermanshah University of Medical Sciences, Kermanshah, Iran

\begin{tabular}{|c|c|}
\hline Article Info & ABSTRACT \\
\hline
\end{tabular}

Received: 2021/02/19;

Accepted: 2021/05/06;

ePublished: 2021/05/18

10.30699/jergon.9.1.15

Use your device to scan and read the article online

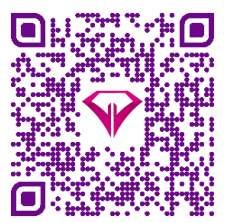

Corresponding Author Payam Khanlari

M.Sc. Student, Department of Ergonomics, School of Public Health, Hamadan University of Medical Sciences, Hamadan, Iran Email:

payamba19@gmail.com
Background and Objectives: Increasing the retention of health care workers in the context of Covid-19 expansion is one of the most important challenges for the health care systems. To design a strategy to maintain health care workers, it is necessary to identify the factors influencing willingness to work or leave the job among health care workers. This study aimed to identify the factors affecting the willingness to work or leave the job among health care workers during the Covid-19 pandemic.

Methods: To identify relevant publications, the online Databases including Scopus, PubMed, Web of Science, and ProQuest were searched on October 20, 2020. Based on the inclusion criteria, only studies that investigated the factors influencing willingness to work or motivation to leave the job among health care workers during the Covid-19 pandemic were included.

Results: Of the 610 studies found through searching, after deleting similar and unrelated studies, a number of 10 cross-sectional articles with a sample size of 15834 subjects were selected. Obtained findings indicated that the willingness to work among health care workers ranged from $61 \%$ to $98.7 \%$ and averaged $83.5 \%$. The results of studies showed that job factors such as work experience, previous work experience in emergency time or Covid-19, workload, cooperation between employees, the relationship between employees and managers, access to personal protective equipment, and welfare facilities were significantly proportional to the willingness of health care workers to work.

Conclusion: The results of this study showed to design a strategy to maintain the health care workers during the Covid-19 pandemic, a broad range of occupational and psychological variables should be considered. Due to the limited number and quality of studies and the extent of influential variables, more studies are needed in this field.

Keywords: Corona, Covid-19, Crisis, Retention, Healthcare Workers

\section{How to Cite This Article:}

Khosravipour M, Khanlari P, Jafari M R. Identifying Occupational and Non-Occupational Factors Affecting the Retention of Health Care Employees in the Covid-19 Pandemic: A Systematic Review Study. Iran J Ergon. $2021 ; 9$ (1) :15-32 


\section{Extended Abstract}

\section{Introduction}

Increasing the retention of health care workers in the context of COVID-19 expansion is one of the most important challenges for the health care systems. This study aimed to identify the factors affecting the willingness to work or leave the job among health care workers during the COVID-19 pandemic.

\section{Methods}

Science, and ProQuest were searched on October 20, 2020. Based on the inclusion criteria, only studies that investigated the factors influencing willingness to work or motivation to leave the job among health care workers during the COVID-19 pandemic were included.

\section{Results}

Of the 610 studies found through searching, after deleting similar and unrelated studies, a number of 10 cross-sectional articles with a sample size of 15834 subjects were selected. The willingness to work among health care workers ranged from $61 \%$ to $98.7 \%$ and averaged $83.5 \%$. The results of studies showed that job factors such as work experience, previous work experience in emergency time or COVID-19, workload, cooperation between employees, the relationship between employees and managers, access to personal protecttive equipment, and welfare facilities were significantly proportional to the willingness of health care workers to work.

\section{Discussion}

In this systematic review study, the factors affecting the motivation of health workers to stay or leave their jobs during the corona pandemic were investigated. After searching in databases with relevant keywords, 10 articles that met the required conditions based on inclusion criteria were reviewed. The results of the study showed that a high percentage of health care workers tend to stay in their jobs during the corona pandemic and care for patients. Although people differed in their views on this issue, some considered this positive sense of willingness to work and care for patients with COVID-19 as part of their job and considered leaving the job to be immoral and unprofessional. On the other hand, one group had a different opinion. They attributed their willingness to work only to the rules of the job and the commitments they made when joining the organization. However, although it can be said that most employees highly tend to work for any reason, there are influential factors that can be particularly effecttive in motivating those employees who work in the organization only on the basis of job commitment.

In this study, we observed that demographic variables have a small effect on the willingness of health care workers to work during the corona pandemic. In other words, none of the studies that examined the gender of individuals found a significant relationship between gender and the level of motivation or willingness to work. Similarly, there was no significant relationship between the variables of having children and their number with the level of willingness to work. Regarding the variables of education level and marital status, although some studies showed a significant relationship, in most studies that examined these variables, there was no significant relationship between these variables and the level of willingness to work. However, the conditions were different for age and income level, and it was found that almost half of the studies that examined the relationship between these variables and the level of willingness to work, reported this relationship as significant. In these studies, it was observed that with increasing age and income, the motivation to leave the job during the pandemic conditions significantly decreases. Overall, although the number of studies is limited, demographic characteristics appear to have a limited effect on employees' willingness to work during the corona pandemic.

Another group of influential factors studied in the studies are job variables. In this study, it was observed that most of these variables are significantly related to the willingness of people to work during the corona pandemic. These results were consistent 
with a review study by Mohammadiaghdam et al. regarding the job variables and physicians staying in deprived places such as villages [30]. Regarding the work experience variable, there was a direct and significant relationship in most studies that examined the relationship between this variable and the desire to work or the motivation to leave the organization; in other words, these studies found that people with more work experience were more likely to want to work. Given that there is a direct relationship between age and work experience, it is likely that the relationship between age and willingness to work, which was observed in some studies, is influenced by people's work history. Similarly, the variable of previous work experience in corona pandemic or emergency situations was significantly associated with a decrease in employee willingness to work in most studies.

Another job-related variable that was significantly associated with employee desire in studies was the job position variable. In all studies that examined this variable, it was found that employees with higher job positions such as head nurses or heads of wards were significantly more inclined to work compared to general nurses. Also, there was a significant relationship between the work department and the willingness of individuals to work in most studies. Employees in departments such as the emergency department and the ICU were less likely to work than those in departments such as surgery and internal medicine. The reason for this can be related to the direct exposure of these people to patients with COVID-19. The other variables examined were the type of employment (full-timepart-time) and the amount of workload. No significant relationship was observed in any of the studies that examined the relationship between employment type and willingness to work. On the other hand, the increase in workload was signifycantly associated with an increase in the tendency to leave work, which is also concluded in a systematic review study [31]. Of course, this can depend on the size of the workforce, the size of the organization, private or public, and the organization being specialized or public.

Anxiety, stress, and fear of caring for people with COVID-19 were other variables that were studied in their relationship to willingness to work. In almost all studies that examined these variables, increased levels of anxiety, stress, and fear associated with COVID-19 care were significantly associated with increased motivation to leave work. On the contrary, increasing the level of knowledge and awareness related to Corona, participating in Coronarelated training programs, increasing the level of social support for employees, effective communication between staff and managers, good communication between staff (nurse and doctors) and patient and increasing sense of teamwork in employees, were other variables that were significantly associated with increased willingness to work or decreesed motivation to leave the job. The availa-bility of appropriate personal protective equipment were another important variable that was signi-ficantly associated with a decrease in the level of fear and anxiety caused by corona and thus increase the level of willingness to work. These factors, which are part of the characteristics of working conditions and environment, are discussed in another study showing the willingness of the employees to stay [32-33].

\section{Conclusion}

The results of this study showed to maintain the health care workers during the COVID-19 pandemic, a bored range of occupational and psychological variables should be considered. Due to the limited number of studies and the extent of influential variables, more studies are needed in this field.

\section{Acknowledgement}

The authors would like to thank all those who supported them in this project.

\section{Conflict of Interest}

The authors declared no conflict of interest. 


\section{مقالة يزووهشى}

شناسايى عوامل شغلى - غيرشغلى تأثير گذار بر ماندَارى كاركنان مراقبتهاى بهداشتى -درمانى در پاندمى كوويد 19: يك مطالعة مرور سيستماتيكى

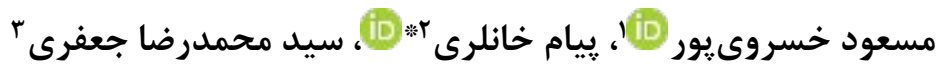

ا . دانشجوى كارشناسى ارشد، گروه مهندسى بهداشت حرفهاى، دانشكده بهداشت، دانشخاه علوم يزشكى كرمانشاه، كرمانشاه، ايران

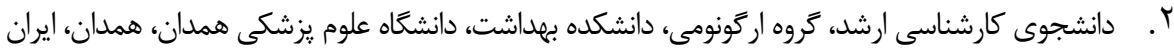

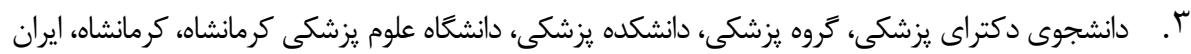

\begin{tabular}{|c|c|}
\hline خلاصه & اطلاعات مقاله \\
\hline 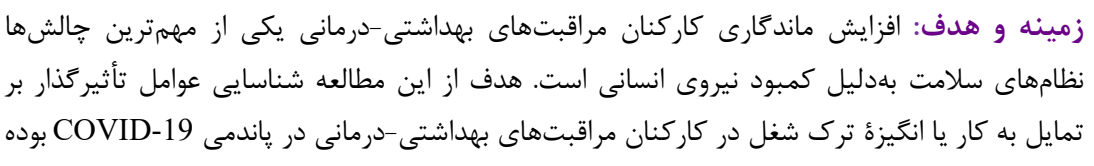 & 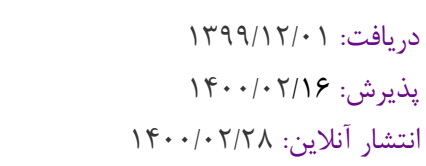 \\
\hline 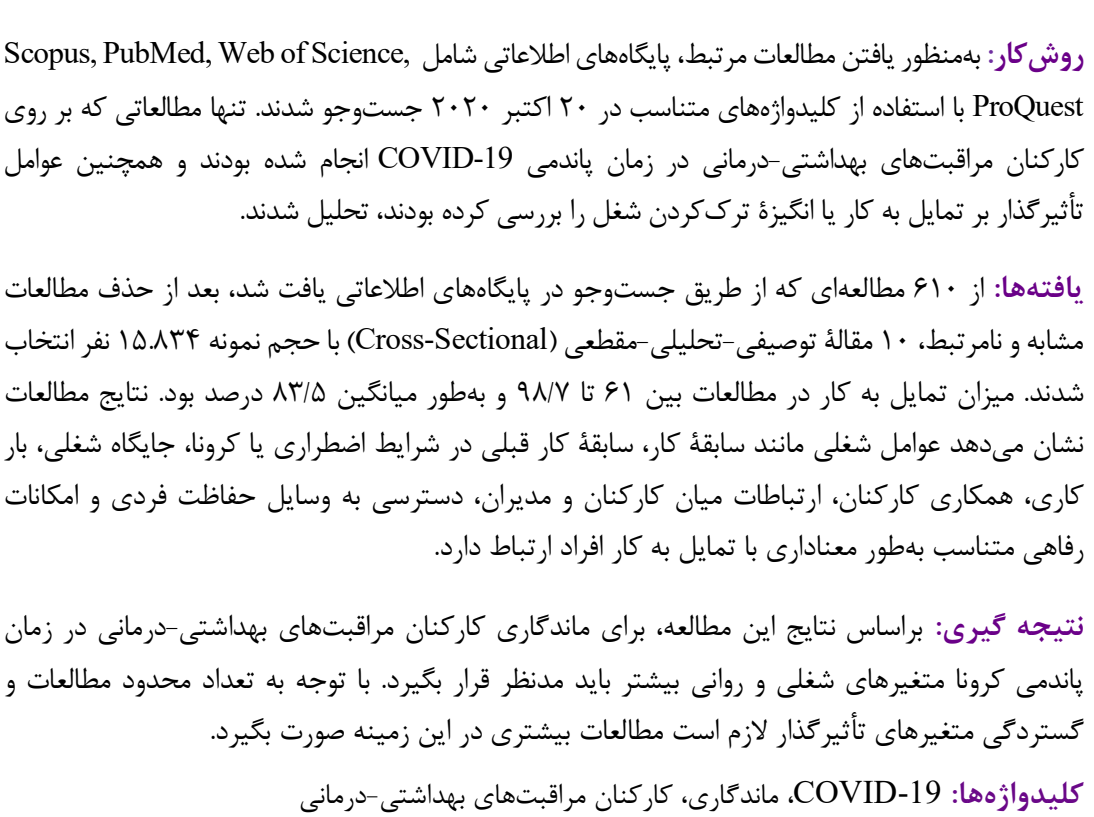 & 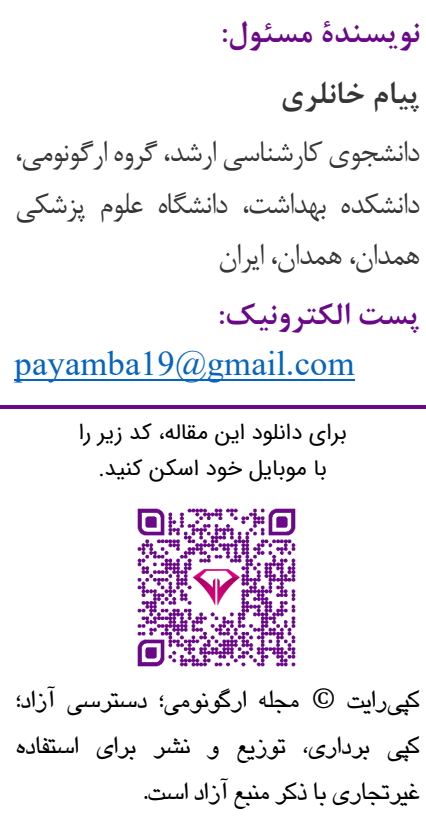 \\
\hline
\end{tabular}

مقدمه

درمان، بلويزه يرستارى در خط مقدم مقابله با اين بيمارىها

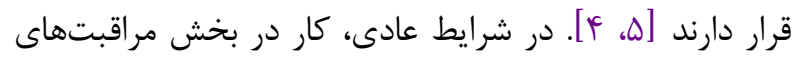

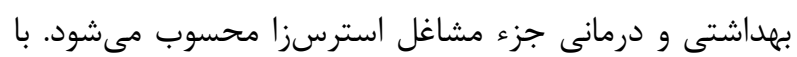

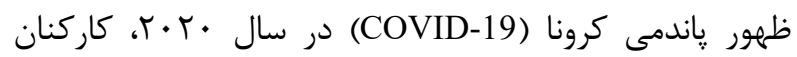
مراقبتهاى بهداشتى كه بهطور مستقيم در تشخيص، درمان و

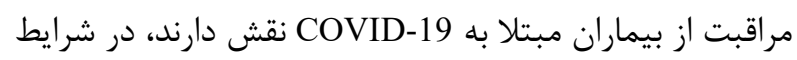
يرتنشى قرار گرفتند. حجم كارى طاقتفرسا، كمبود تجهيزات
همهَيرى بيمارىهاى عفونى مختلف مانند آنفلوانزاى

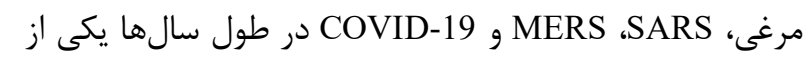

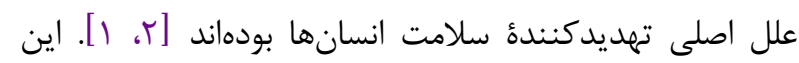
بيمارىها براى نظام سلامت هر كشور فراتر از تهديد بوده و

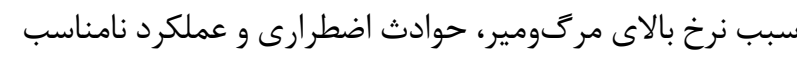

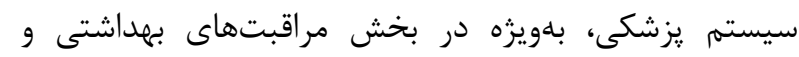

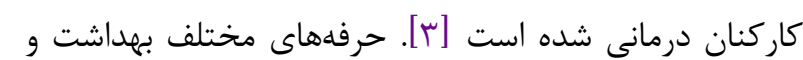




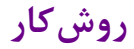

مطالعهُ حاضر مطابق با كايدلاين PRISMA كزارش شده

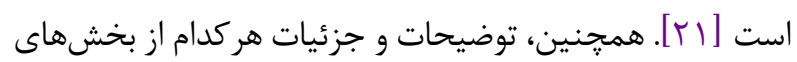

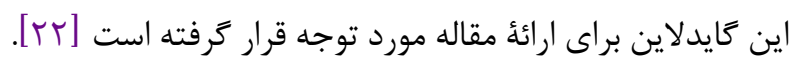

\section{معيارهاى شايستكى يا ورود}

معيارهاى ورود در اين مطالعه بهصورت زير و و براساس PICOST

!. جمعيت مورد مطالعه (Study population): جمعيت مورد مطالعه كاركنان مراقبتهاى بهديت مورد ماشتى

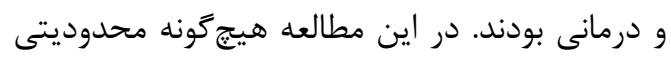
از نظر سن، جنسيت و نززاد در نظر كرفته نشده است.

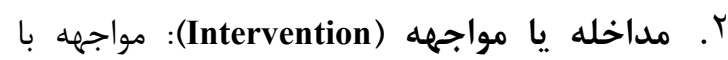
بيماران مبتلابه بيمارى كرونا ويروس (COVID-19).

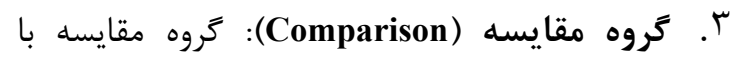

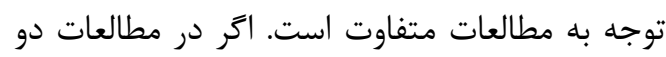

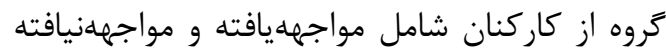

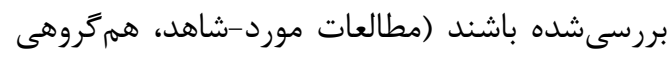

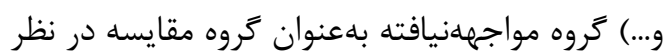
كرفته مىشود، ولى اكر كروه مقايسه وجود نداشته باشد و همأ شركتكنيدكان مواجههيافته باشند (مطالعات توصيفى-مقطعى و...)، تروه مقايسه وجود

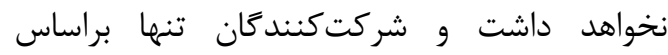

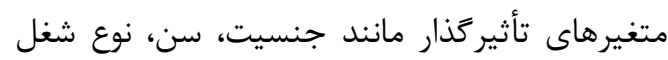
و.... مقايسه خواهند شد.

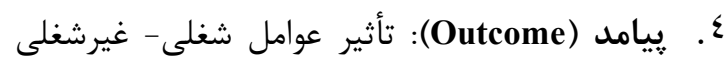

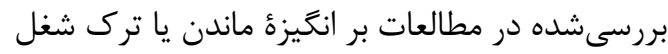

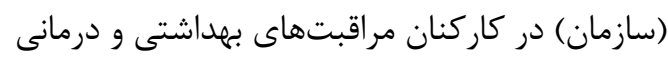

در مواجهه با بيماران مبتلا با COVID-19.

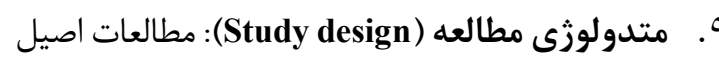

يزروهشى (Original Research) جستوجو در پايعًاههاى اطلاعاتى بامنظور شناسايى مطالعاتى كه ارتباط مورد نظر را بررسى إنى إنى كردهاند، پايڤاههاى اطلاعاتى زير بررسى شدند.

1. PubMed (https://www.ncbi.nlm.nih.gov/pubmed/)

2. Scopus (https://www.scopus.com)

3. Web of Science (https://www.webofknowledge.com)

4. ProQuest (https://www.proquest.com/index)
محافظت شخصى، كمبود داروهاى خاص و احساس عدم حمايت كافى از جمله طيف گستردهاى از متغيرها هستند كه سلامت

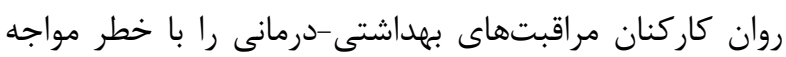

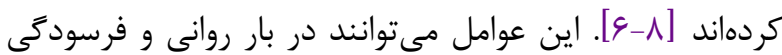

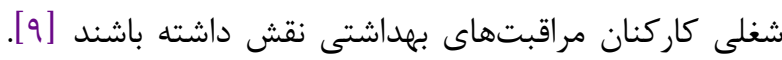

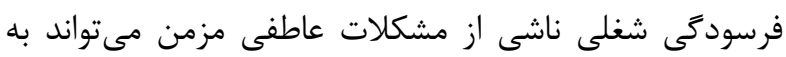

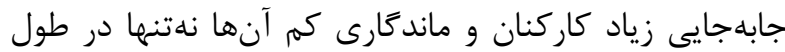

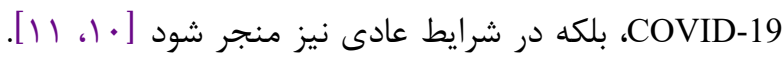

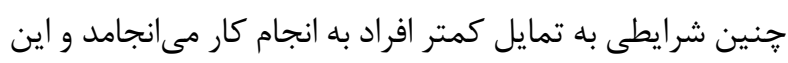
بىتمايلى به اجراى كار سبب كاهش كيفيت مراقبت و افزايش

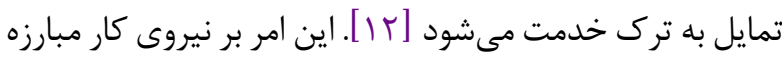

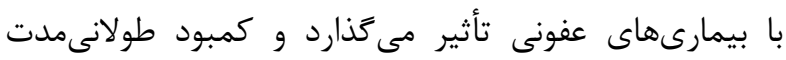

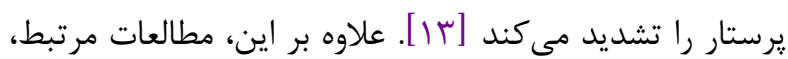

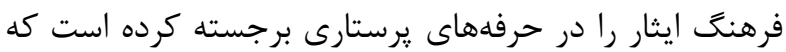
ممكن است منجر به نارضايتى شغلى، فرسودىى شغلى آنى

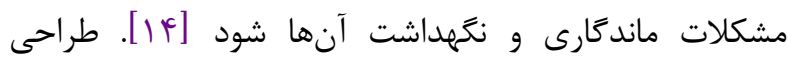
برنامههاى راهبردى در جهت مديريت كمبود نيروى انسانى در

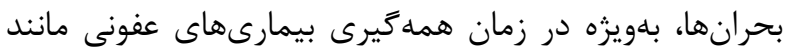

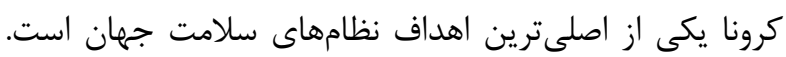
بهمنظور تحقق اين هدف، شناسايى متغيرهاى تأثيركذار بر أردان ماندكارى كاركنان ضرورى است. طى دو دهؤ كذشته، مطالعات

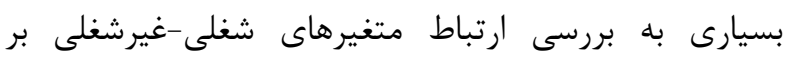

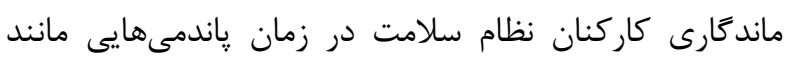

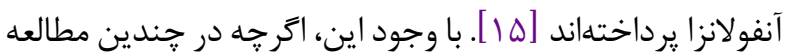

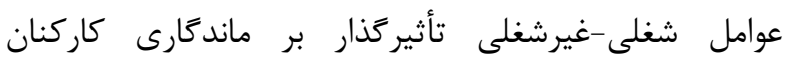

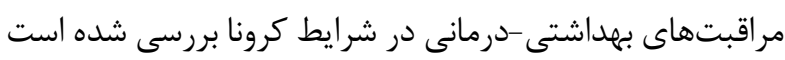

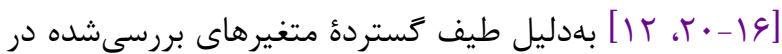
مطالعات و همجنين تناقض در برخى متغيرهاى مشترك ارتباط

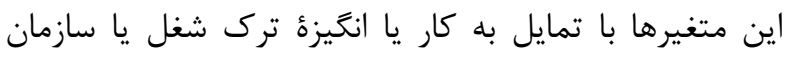

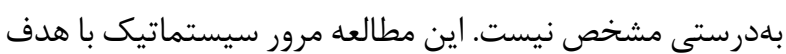
تعيين عوامل شغلى-غيرشغلى تأثير كذار بر ماندكارى كاركنان

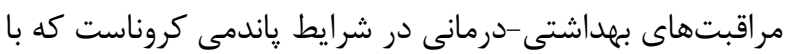

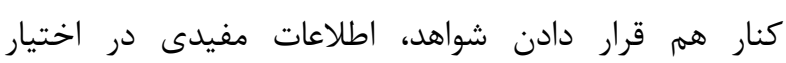
سياست كذاران و افراد مرتبط در مديريت منابع انسانى در شرايط اضطرارى قرار مى دهد. 
شدند. هريك از پايكاههاى اطلاعاتى ذكرشده با استفاده از

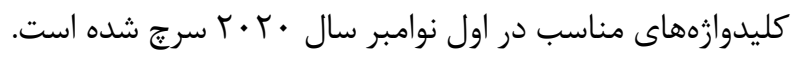

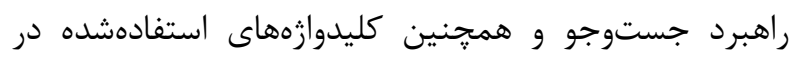
جدول ال ارائه شده است.
علاوهبر پِايخاههاى اطلاعاتى فوق، يايگاه مجلات فارسى SID و مجلات معتبر و مشهور مرتبط در اين زمينه مطالعه نيز

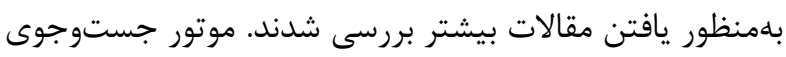
Grey ( نيز بهمنظور يافتن مقالات خاكسترى Google Scholar

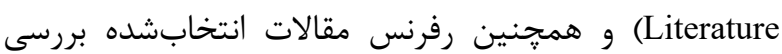

جدول ا.. راهبرد جستو جو

كليد وازهها سر ج شده در عنوان و جكيده

رديف بخشها

nurse* OR physician* OR doctor* OR "Health Workers" OR "Healthcare Workers" OR "Health care Workers" OR "health Providers" OR "healthcare Providers" OR "health care Providers" OR "health practitioners" OR "healthcare practitioners" OR "health care practitioners" OR "health Professionals" OR "healthcare Professionals" OR "health care Professionals" OR "health Staff" OR "healthcare Staff" OR "health care Staff" OR "medical Staff" OR "hospital Staff" OR "health workforce" OR "healthcare workforce" OR "health care workforce" OR "health Manpower" OR "healthcare Manpower" OR "health care manpower" OR "health Personnel" OR "healthcare Personnel" OR "health care Personnel" OR "hospital Personnel" OR "medical Personnel" coronavirus OR "COVID-19" OR outbreak* OR epidemic* OR pandemic*

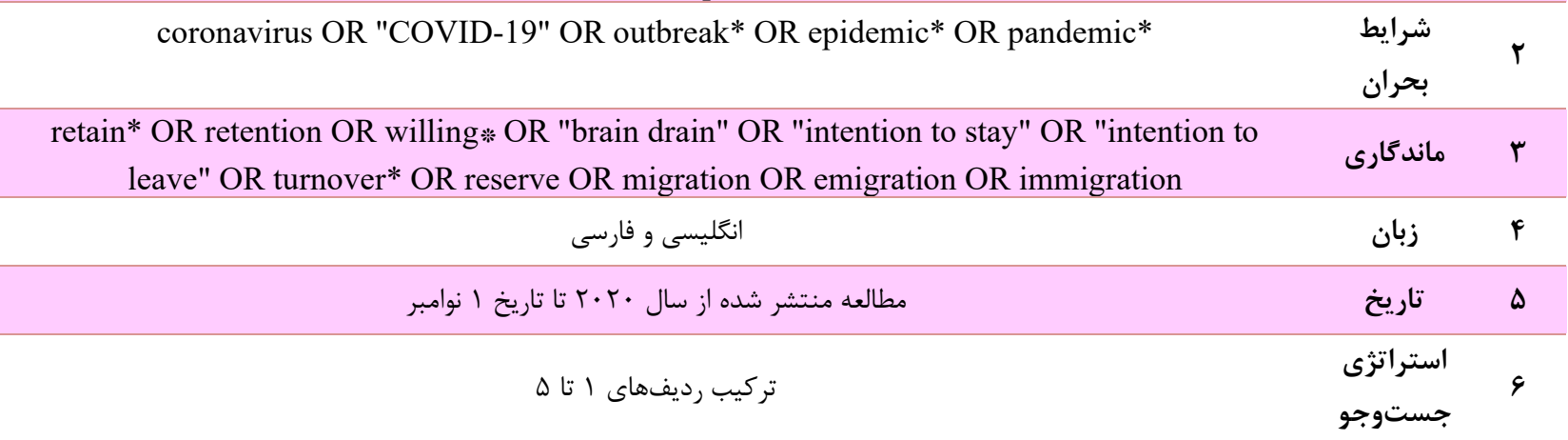

؟. مطالعاتى كه در زمان پاندمى كرونا (COVID-19)

$$
\text { انجام نشده بودند. }
$$

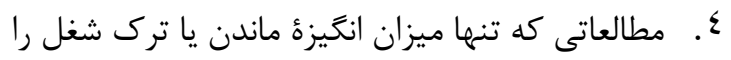

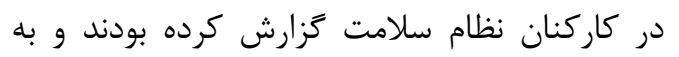

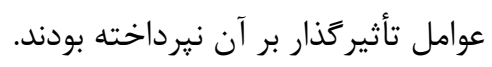

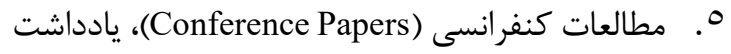

Letter To ) نامه به دبير (Commentaries or Notes)

(Editor و مقالات مرورى (Review Articles).

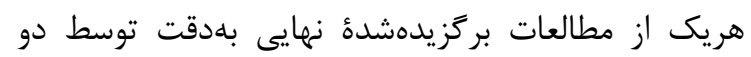

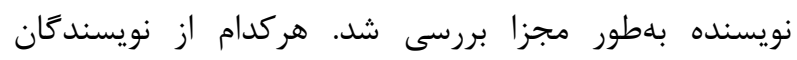

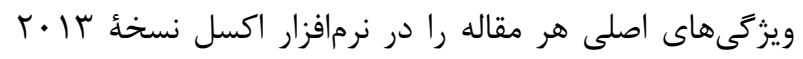

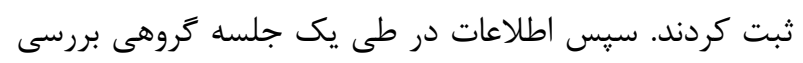

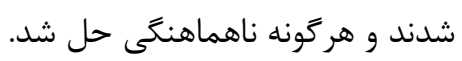

\section{انتخاب مطالعات}

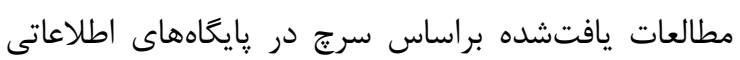

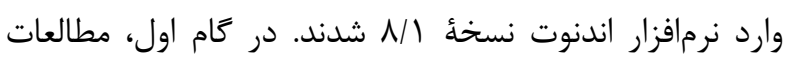

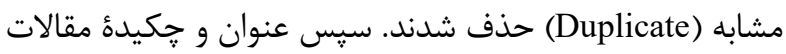
بligibility) باقىمانده براساس معيارهاى درنظر كرفتهات

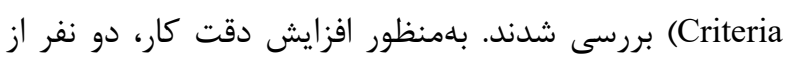

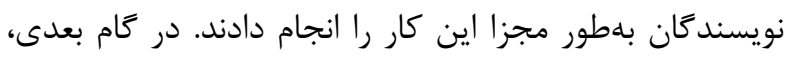

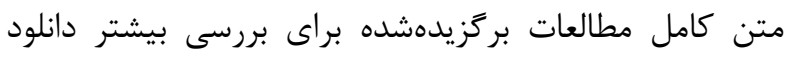

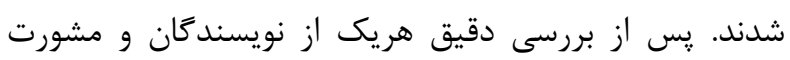

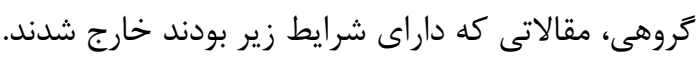

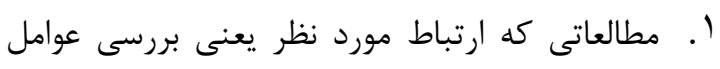

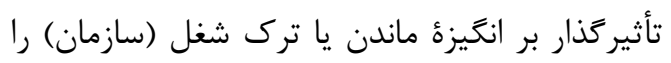

$$
\text { بر برسى نكرده بودند. }
$$

r مراقبتهاى بهداشتى و درمانى يا دانشجويان انجام 
مورد نظر را بررسى نكرده بودند، متن كامل هN مقاله دانلود و

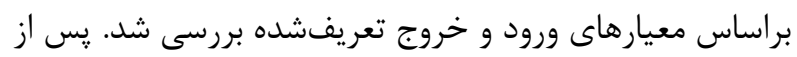

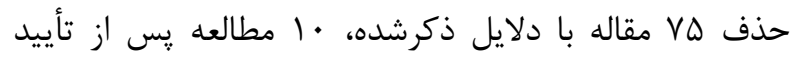

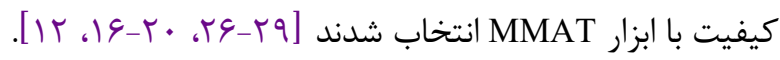

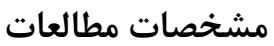

خلاصهاى از مشخصات مطالعات واردشده در اين مطالعه در مدات

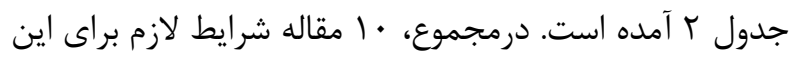

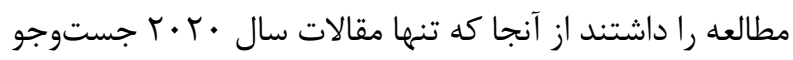

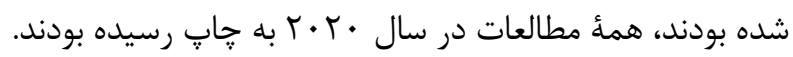

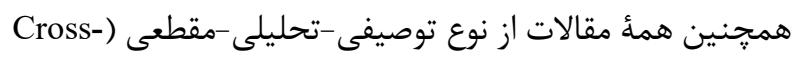

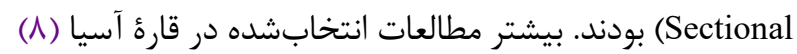

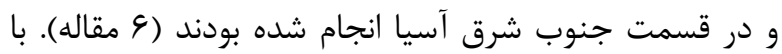

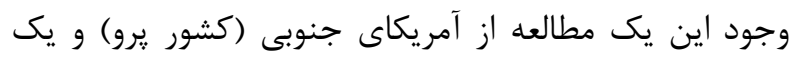

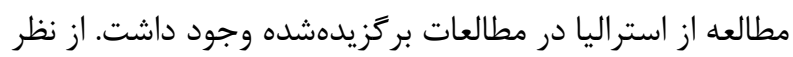

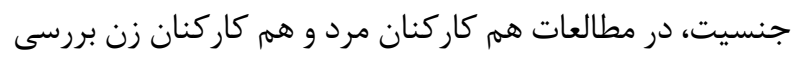

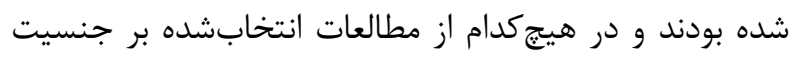

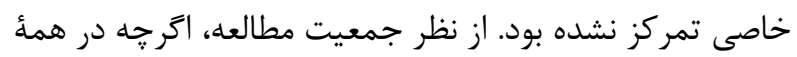

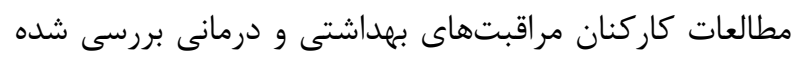

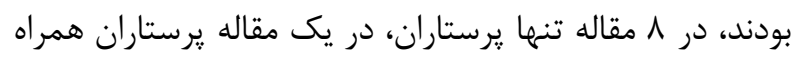

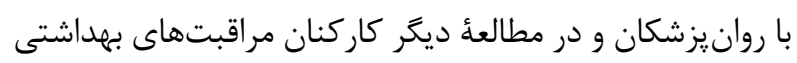
و درمانى شامل يرستاران، يزشكان، داروسازان و... مطالعه شدند.

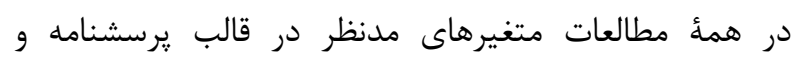

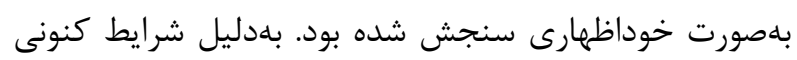

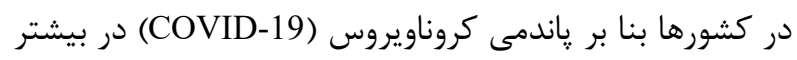
مطالعات يرسشنامه در بستر وب و شبكدهاى مجازى براى براى

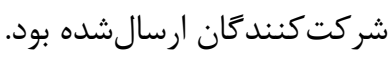

\section{نوع دادهها}

براى هريك از مقالات بركزيده، دادهاى زير جمعآورى

شنن.

! ب. نويسندكان و سال جاب مقاله؛

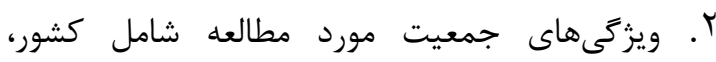

جنسيت، نوع (شغل) كاركنان سلامت و حجم مورد نمونه؛

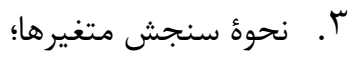

$$
\begin{aligned}
& \text { ع. . يافتههاى مهمه. } \\
& \text { ارزيابى كيفيت مطالعات }
\end{aligned}
$$

بمنظور ارزيابى كيفيت يا خطر تورش در مطالعات از ابزار ن نسخة

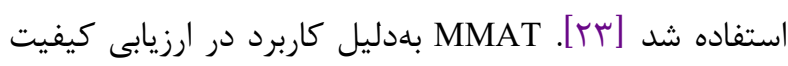

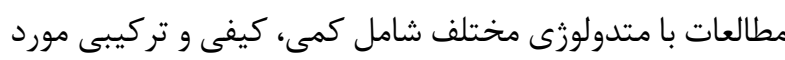

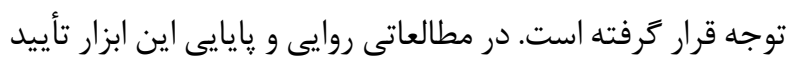

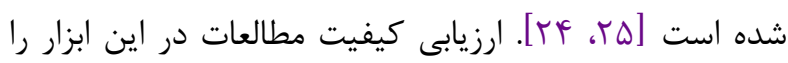

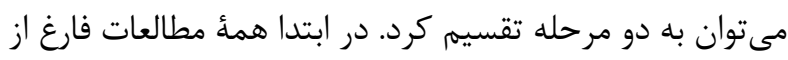

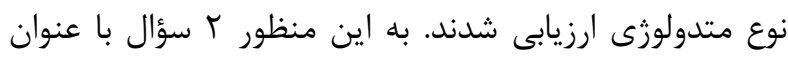

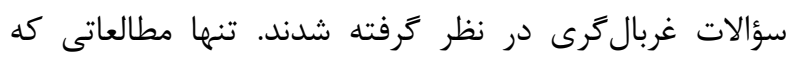

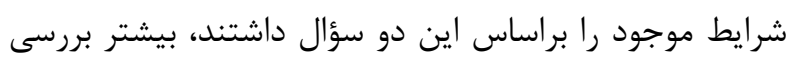

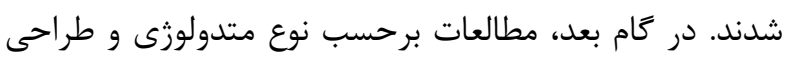

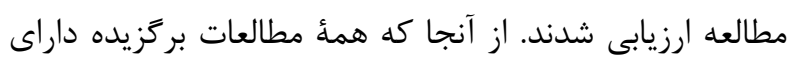

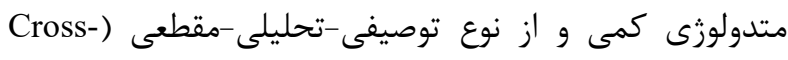
(sectional

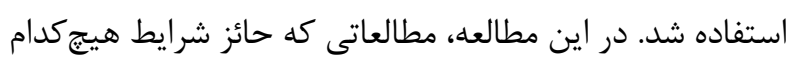

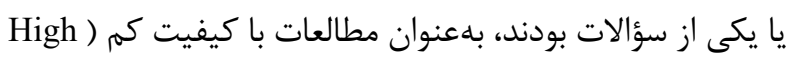

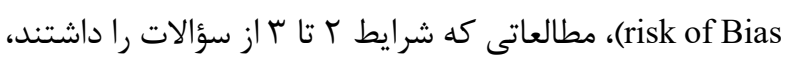

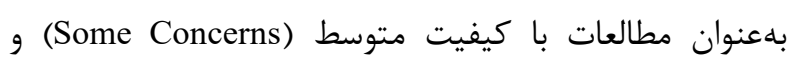
مطالعاتى كه شرايط تمامى يا جهار مورد از سؤالات را داشتند، متهن

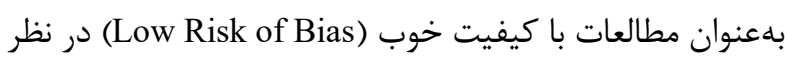
كرفته شدند

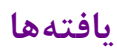

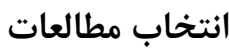

همانطور كه در شكل ا مشخص است، • ا9 مطالعهاى كه مهات

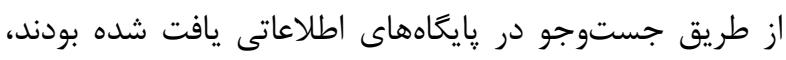

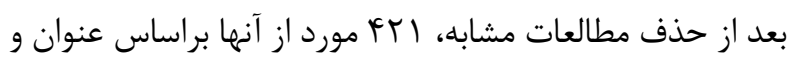

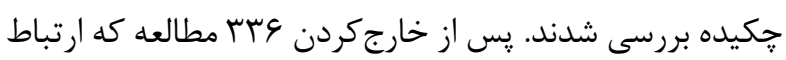



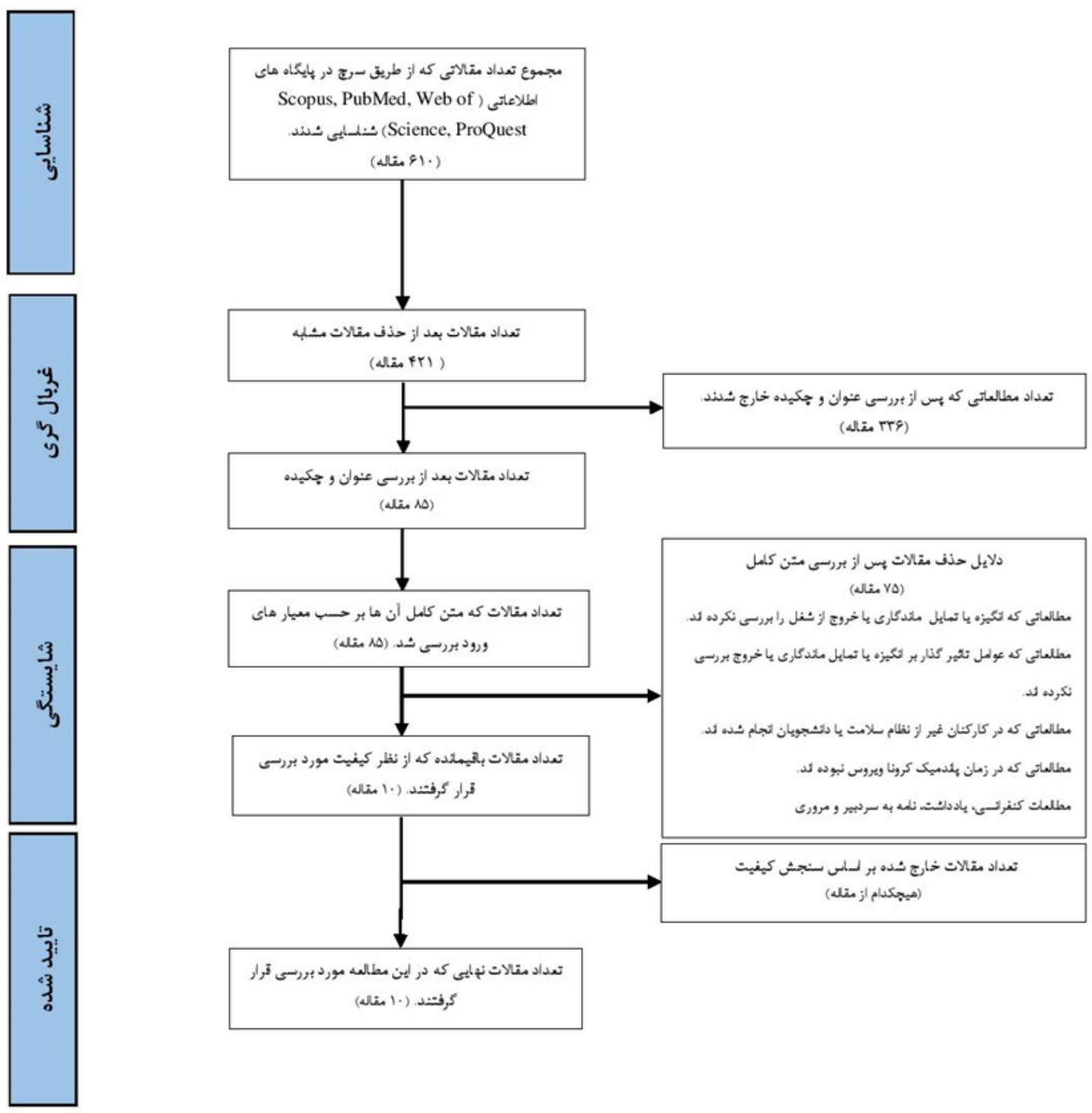

شكل ا. فلوحارت فرايند مرور سيستماتيك 
I. همبستخى معنادارى بين نكرانى ايجادشده ناشى از كرونا

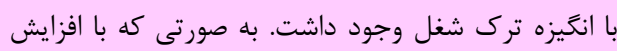

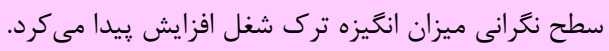

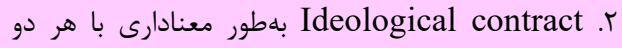

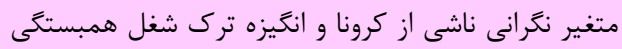
منفى داشت.

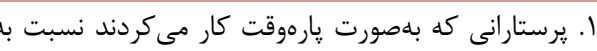

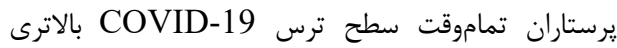
داشتند (P<0.05).

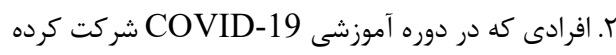
بودند بهطور معنادارى ترس از بـ همبستخى معنادار مثبتى بين سطح ترس از-COVID

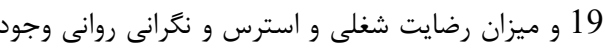
f. برستان شاغل در بيمارستانهاى بزرى (تخت بيشتر از (TD.

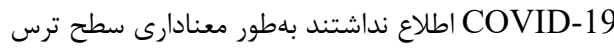
COVID-19 ز بيشترى داشتند. هـ ارتباط معنادارى معكوسى بين سطح ترس از لـ 19 و انكَيزه ترك كردن سازمان يا شغل وجود داشت دئ.

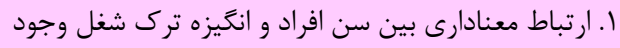
داشت بهكونهاى كه با افزايش سن شانس ترك شغل كاهش

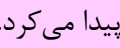
r. انكَيزه ترك شغل شرد بهطور معنادارى در كاركنان بخش خصوصى نسبت به بخش دولتى بيشتر بود.

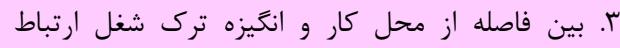

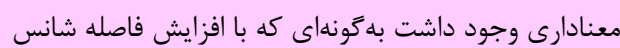
ترك شغل افزايش קيدا مى كرد.
بررسى ارتباط نغرانى روانى ناشى انسى از , COVID-19 متغيرهاى موردبررسى

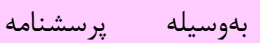
محقق ساخته سنجيده و جمعآورى كرديدند. انكيزه ترك كردن شغل و همجنين تأثير

ideological contract ارتباط

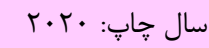

كشور: ياكستان

نوع مطالعه: - Cross sectional

g Irshad

همكاران

جنسيت: مرد و زن ان

حجم نمونه: IV

يرستاران

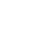

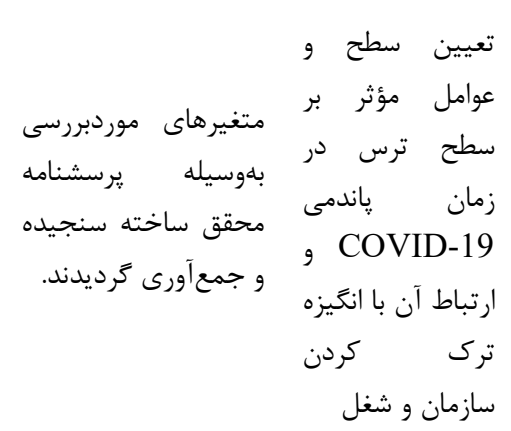

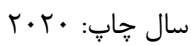

كشور: فيلييين

نوع مطالعه: - نور: فيلين sectional

gabrague

يرستاران

de los Santos

حجم نمونه: إلى

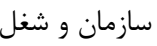

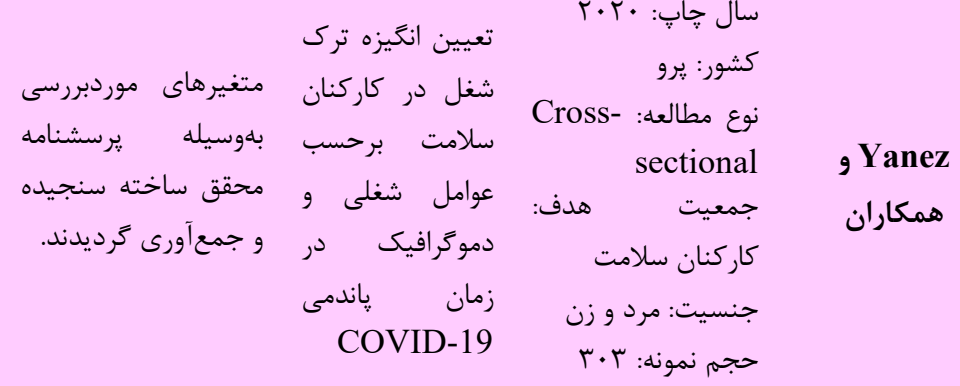

ا. ارتباط معنادارى بين سن افراد و انخيزه ماندن در شغل

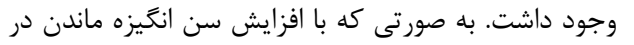

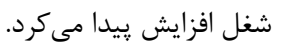

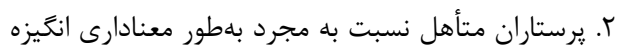
ماندن بيشترى داشتند.

$$
\begin{aligned}
& \text { تعيين ارتباط } \\
& \text { ب. (support }
\end{aligned}
$$

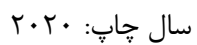

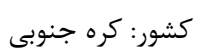

نوع مطالعه: -Cross sectional

همكاران يرستاران

جنسيت: مرد و زن 


\section{يافته هاى مهمه}

\section{روش سنجش}

متغير ها

هدف

مشخصات مطالعه

نويسندكان

r. يرستاران با درآمد با (بيشتر از . •هَ دلار) نسبت به ديخر

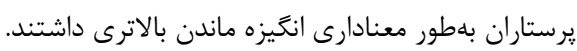

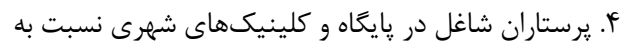

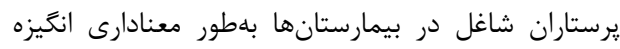
ماندن بيشترى داشتند.

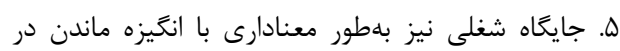

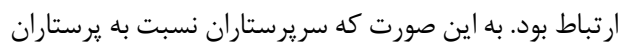

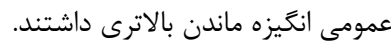

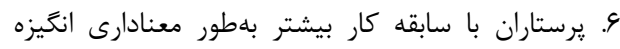
ماندن بيشترى داشتند.

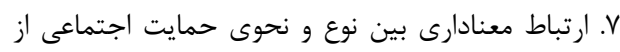

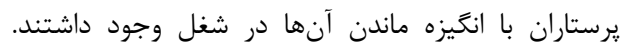

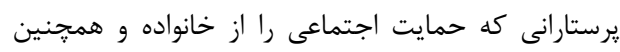
رسانهاى عمومى دريافت كرده بودند انكَيز ماندن بيشترى انداني داشتند.

\begin{tabular}{|c|c|c|c|c|}
\hline 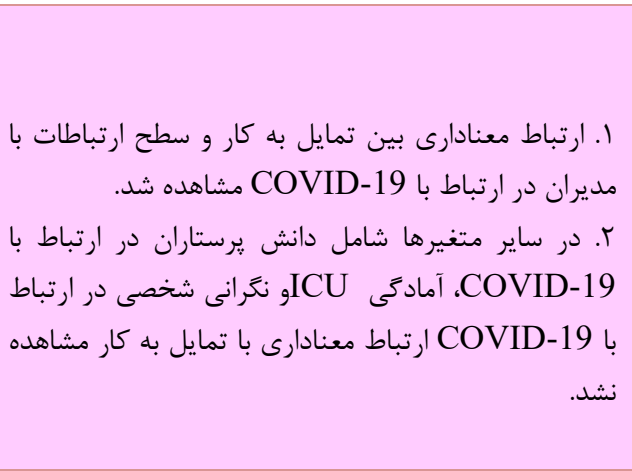 & 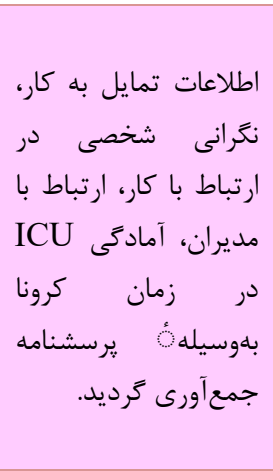 & 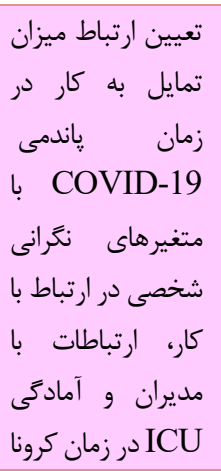 & 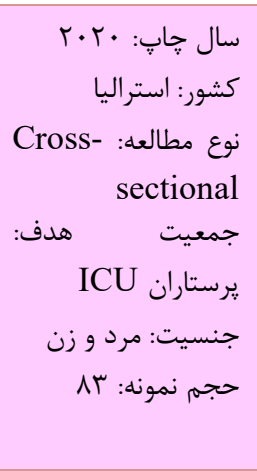 & همكاران \\
\hline 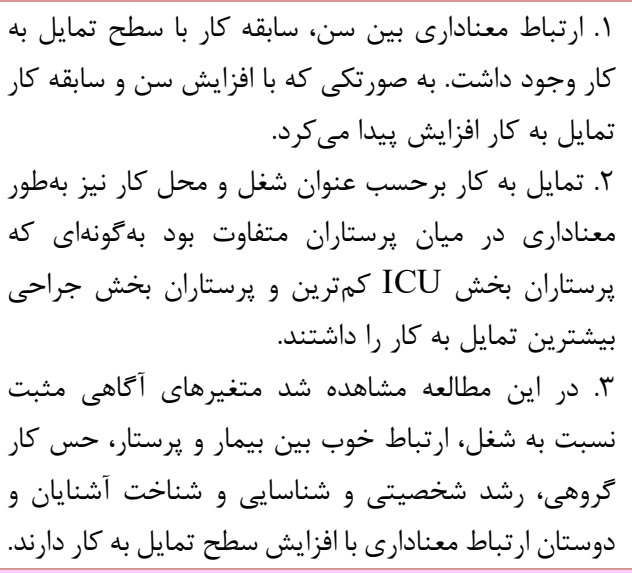 & 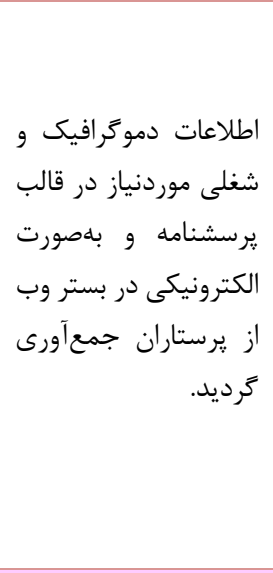 & 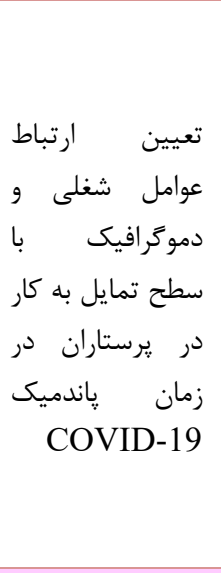 & 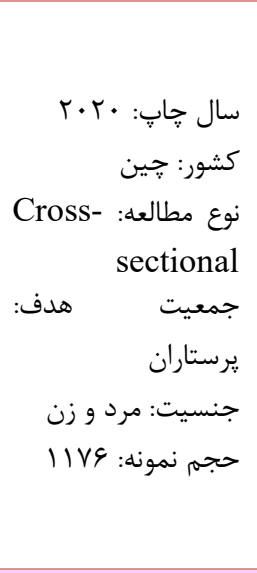 & $\begin{array}{l}\text { Wu } \\
\text { همكاران }\end{array}$ \\
\hline 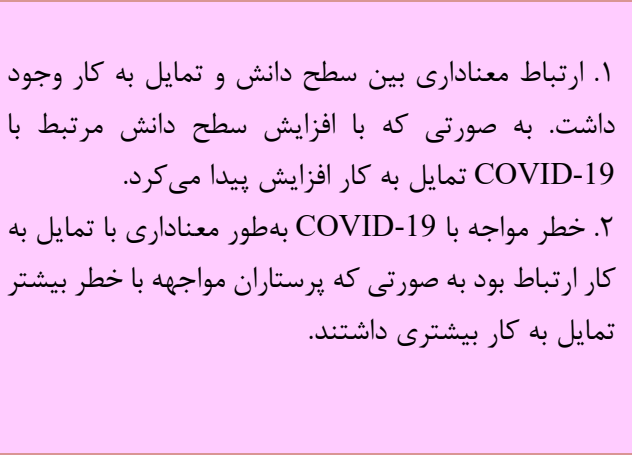 & 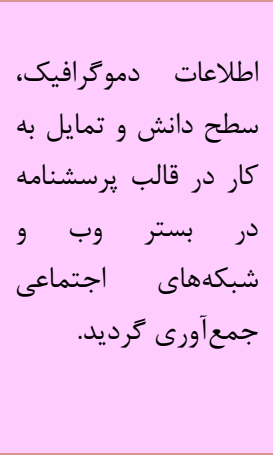 & 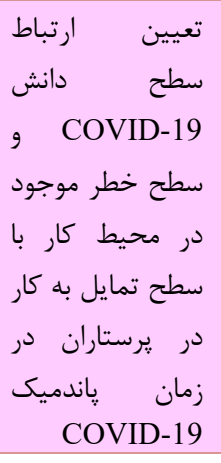 & 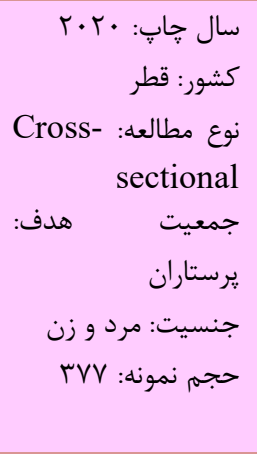 & $\begin{array}{c}\text { Nashwan } \\
\text { همكاران }\end{array}$ \\
\hline
\end{tabular}

\author{
يرستاران در زمان \\ ياندمى \\ COVID-19
}

حجم نمونه: TVV

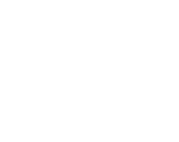




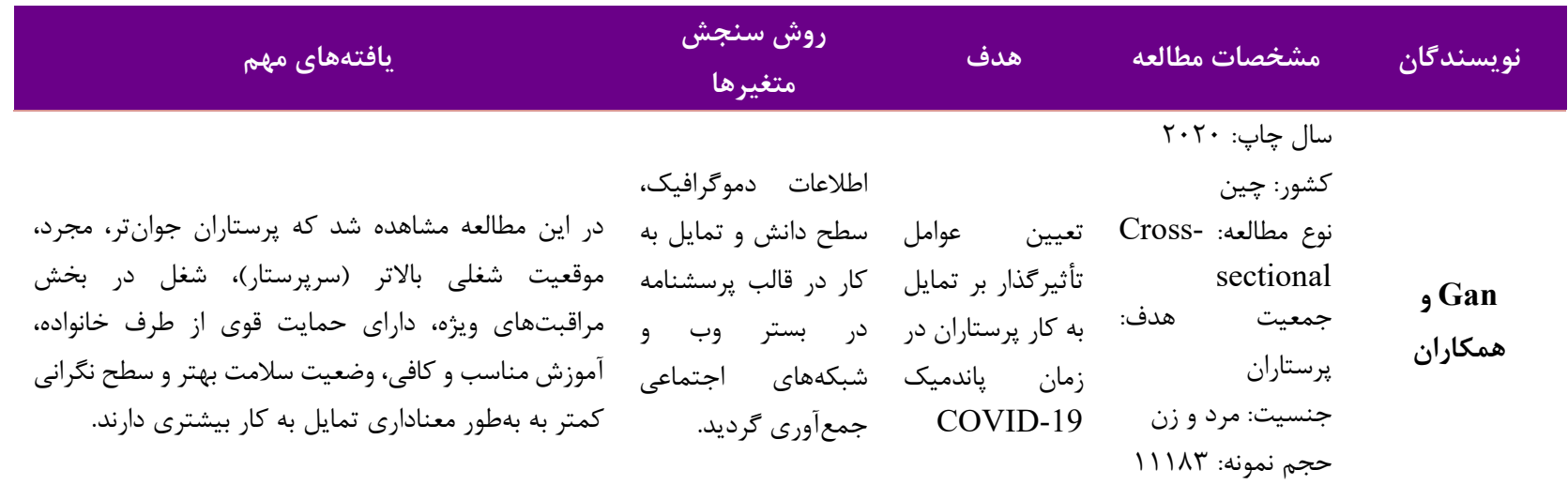

\begin{tabular}{|c|c|c|c|c|}
\hline 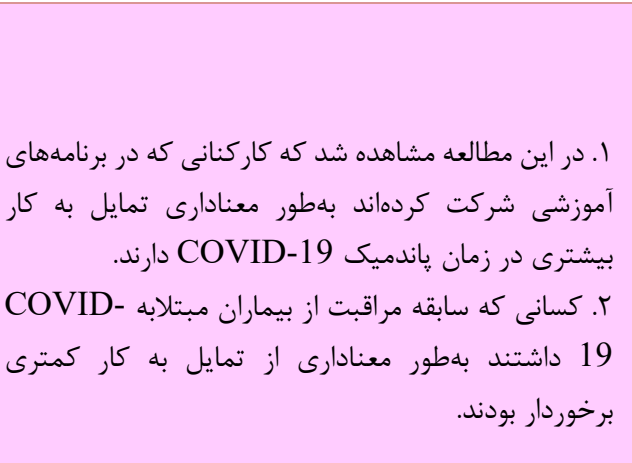 & 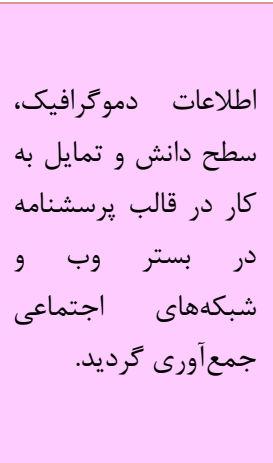 & 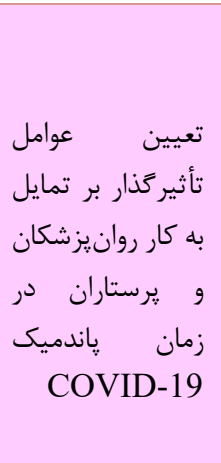 & 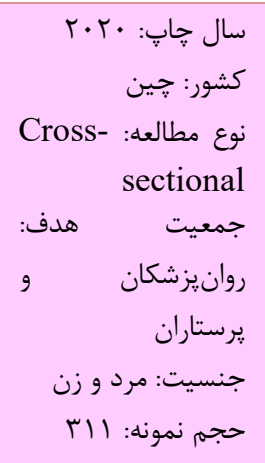 & $\begin{array}{c}\text { همكاران } \\
\text { Shi }\end{array}$ \\
\hline 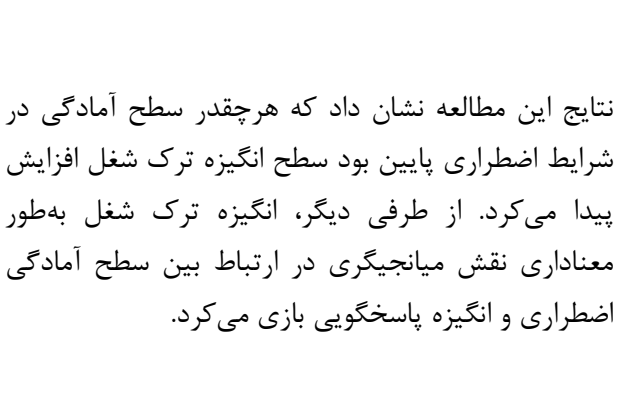 & 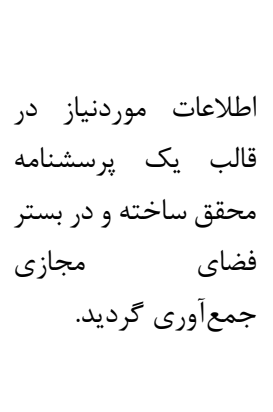 & 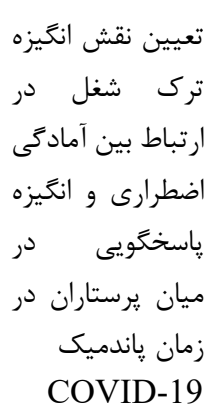 & 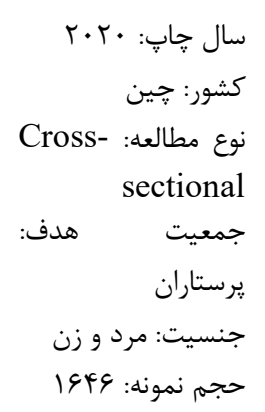 & همكاران \\
\hline
\end{tabular}

است، اثر مداخلهكرها (Confounding Effects) يكى از

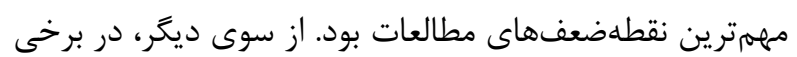

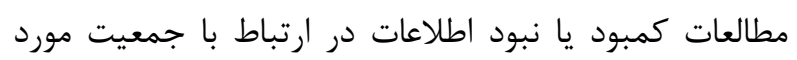

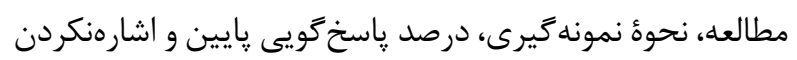

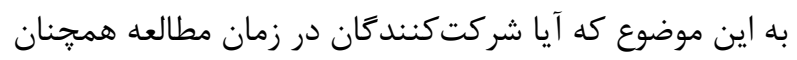

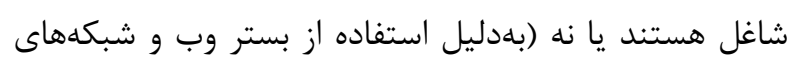
اجتماعى) از ديخر عوامل خطر افزايش تورش در مطالعات بودند.

\section{ريسك تورش در مطالعات}

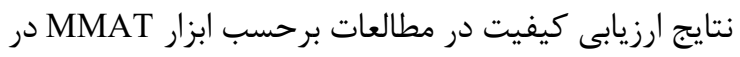

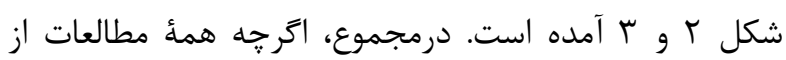

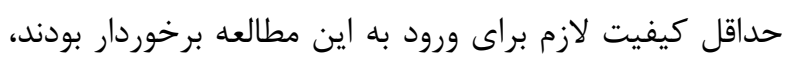

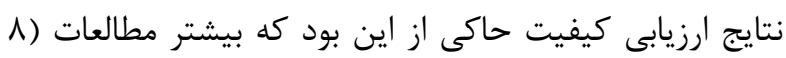

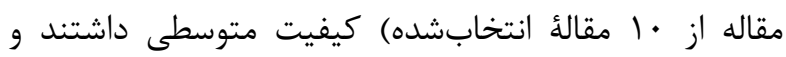

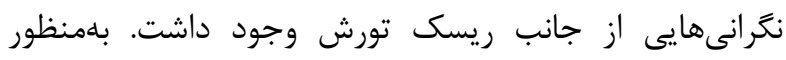
بررسى دليل تورش در مطالعات، همانطور كه در شكل ب آمده 


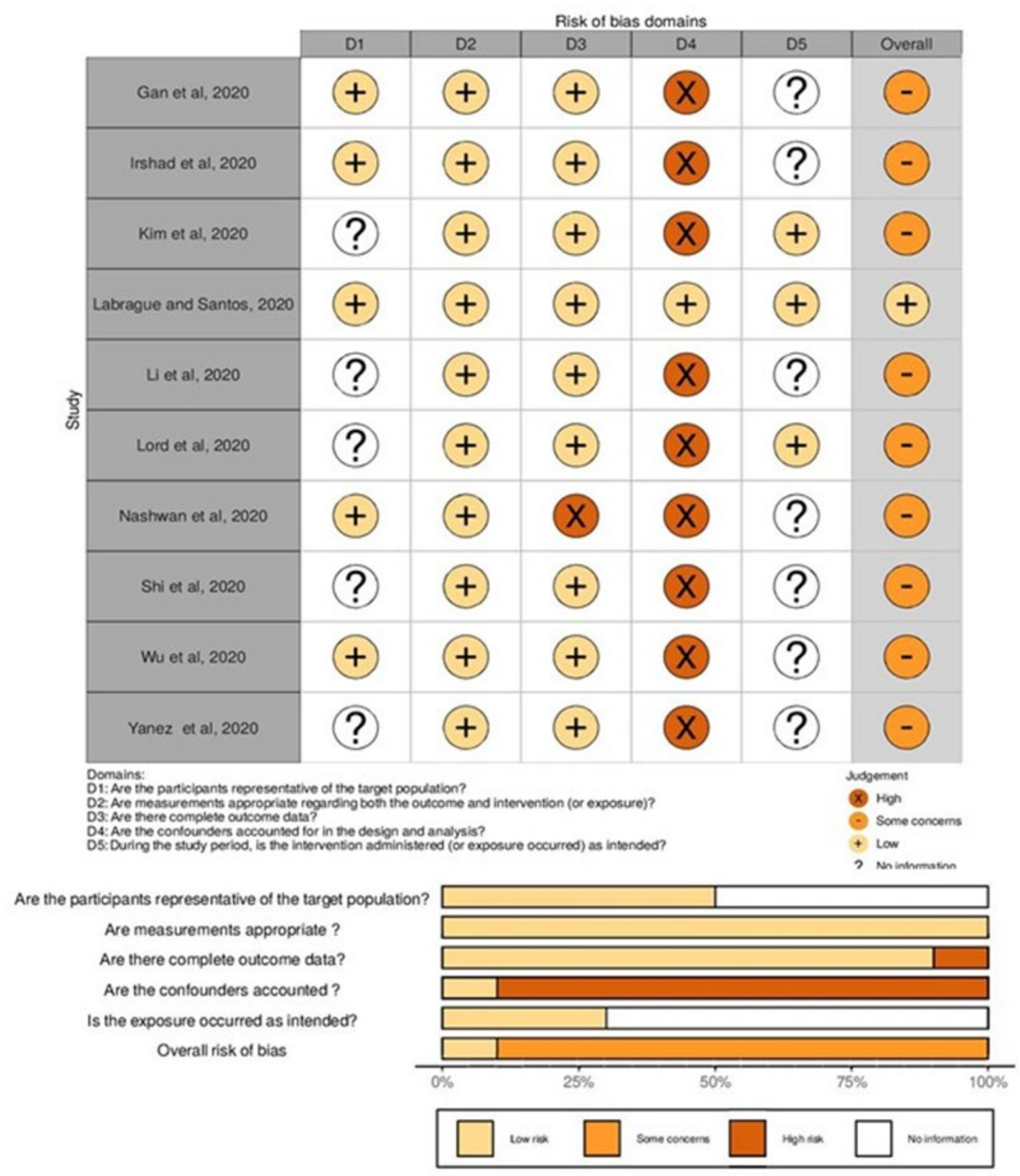

MMAT شكل جزئيات ارزيابى كيفيت مطالعات واردشده براساس ابزار كيفيت

كه حداقل در دو مطالعه بررسى شدهاند، ارائه شده است. بر اين

اساس، مطالعات به سه كروه زير تقسيم شدند.

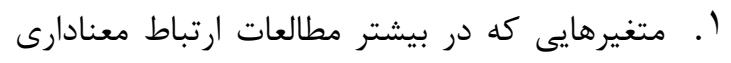

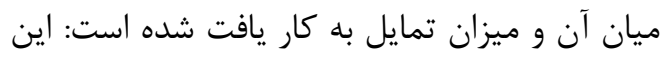
كروه از متغيرها شامل سابقه كار، ديارتمان كارى

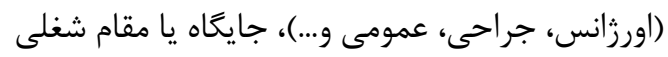

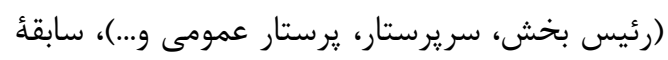
كار قبلى در شرايط اضطرارى يا كرونا، سطح نكرانى

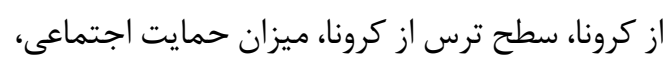

\section{نتايج مطالعات}

ميزان تمايل به كار در كاركنان مراقبتهاى بهات ماتهاشتى

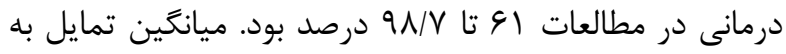

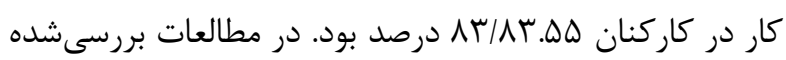

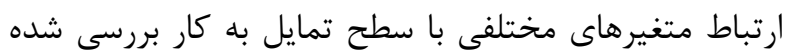

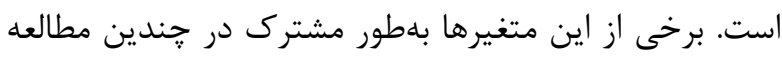

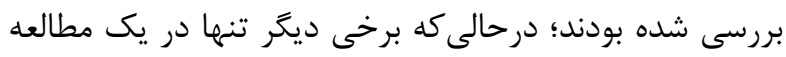

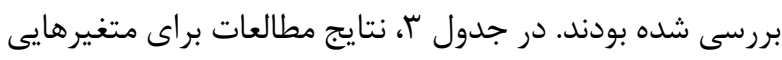




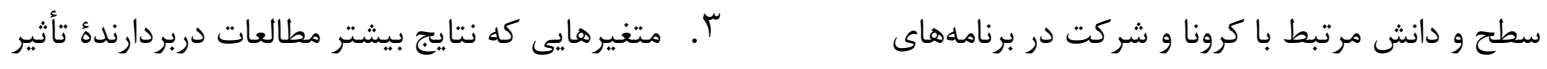

$$
\begin{aligned}
& \text { نداشتن آنها بر تمايل افراد به كار در شرايط پِاندمى بائق }
\end{aligned}
$$

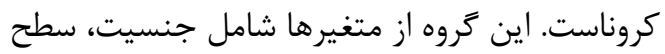

$$
\begin{aligned}
& \text { تحصيلات، وضعيت تأهل، فرزندداشتن، تعداد فرزندان } \\
& \text { و نوع كار (تماموقت-هاره وقت) است. }
\end{aligned}
$$

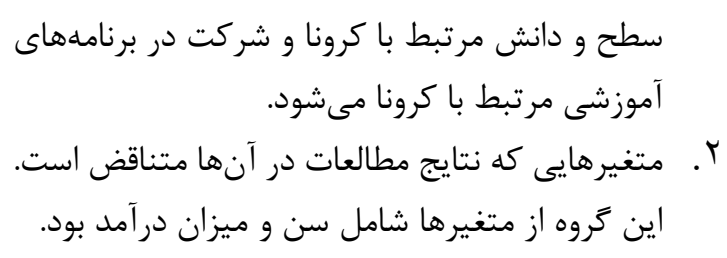$$
\text { آموزشى مرتبط با كرونا مىشود. }
$$

\begin{tabular}{|c|c|c|c|c|c|c|c|c|c|c|c|}
\hline \multicolumn{10}{|c|}{ نويسنده اول مطالعات } & \multirow{2}{*}{ متغيرها } & \multirow{2}{*}{ رديف } \\
\hline Lord & Shi & Gan & Nashwan & $\mathrm{Wu}$ & Irshad & Kim & Yanez & Labrague & $\mathrm{Li}$ & & \\
\hline NS & NS & NS & - & NS & - & NS & NS & - & NS & جنسيت & 1 \\
\hline NS & NS & NS & - & S & - & $\mathrm{S}$ & $\mathrm{S}$ & - & - & سن & $r$ \\
\hline- & NS & S & - & NS & - & - & NS & - & $\mathrm{S}$ & تحصيلات & $r$ \\
\hline- & NS & NS & - & - & - & $\mathrm{S}$ & - & - & - & تأهل & p \\
\hline- & - & - & - & NS & - & - & - & - & NS & فرزند & $\Delta$ \\
\hline- & - & $\mathrm{S}$ & - & NS & - & - & NS & - & - & فرزندان & 9 \\
\hline NS & - & S & - & S & - & S & - & - & $\mathrm{S}$ & سابقه كار & v \\
\hline- & $\mathrm{S}$ & $\mathrm{S}$ & - & $\mathrm{S}$ & - & - & - & - & S & 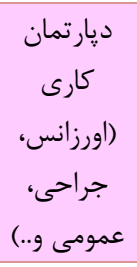 & $\wedge$ \\
\hline NS & - & - & - & - & - & - & NS & - & - & 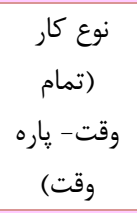 & 9 \\
\hline- & - & - & - & NS & - & $\mathrm{S}$ & - & - & - & مرآ ميزان & 1. \\
\hline- & - & $\mathrm{S}$ & - & $\mathrm{S}$ & - & $\mathrm{S}$ & - & - & S & 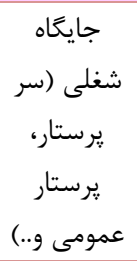 & 11 \\
\hline- & $\mathrm{S}$ & $\mathrm{S}$ & - & - & - & NS & - & - & $\mathrm{S}$ & 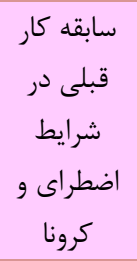 & ir \\
\hline $\mathrm{S}$ & - & $\mathrm{S}$ & - & - & S & - & - & - & $\mathrm{S}$ & سطرانى & Ir \\
\hline
\end{tabular}

جدول س. خلاصهٔ نتايج متغير هاى تأثير گذار بر تمايل به كار در مطالعات 


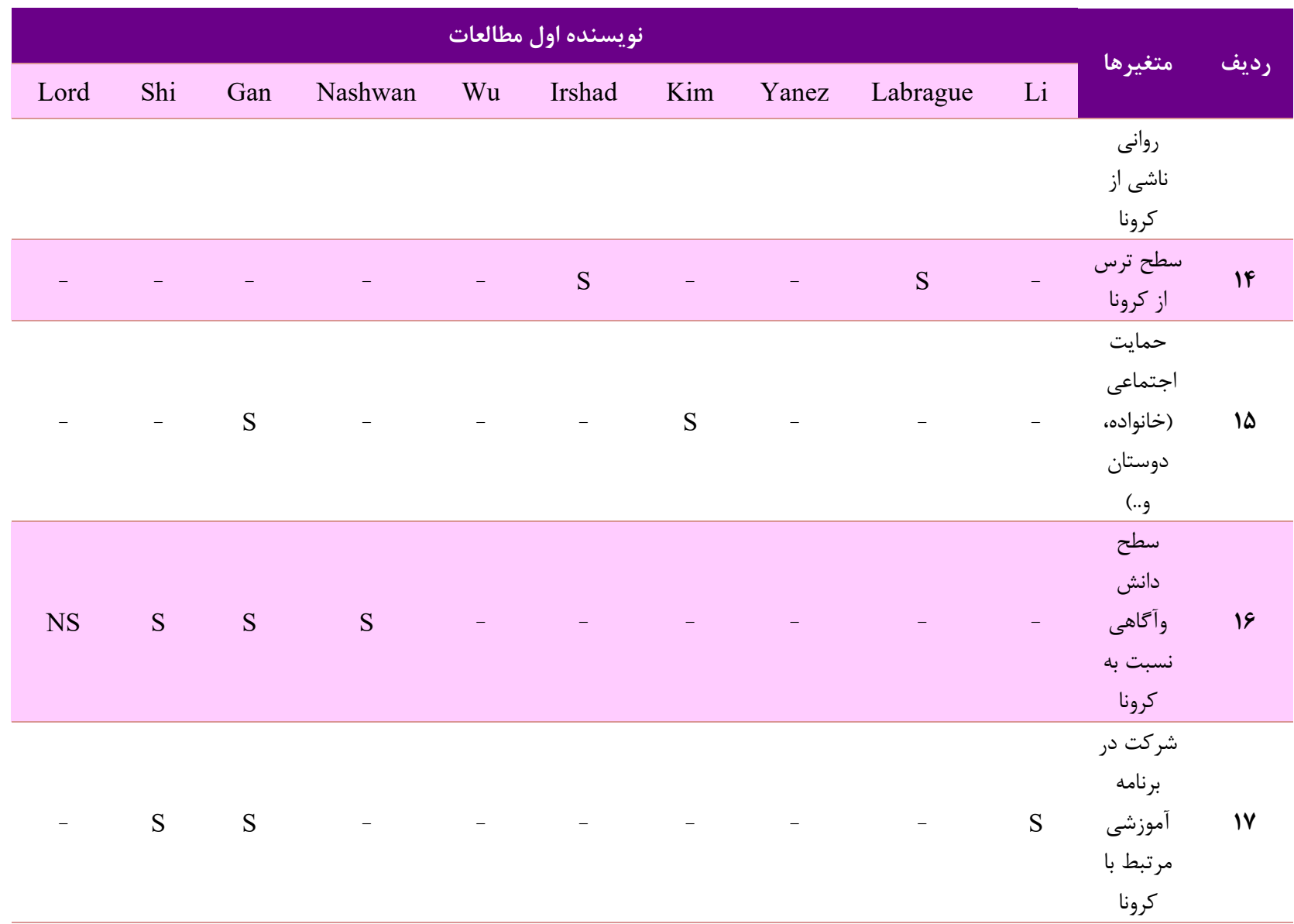

سلامت تمايل دارند در شغل خود در زمان ياندمى كرونا بماند و از

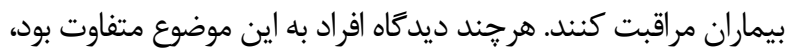
برخى اين حس مثبت تمايل به كار و مراقبت از بيماران مبتلابه كرونا را جزئى از شغل خود مى حانستند و ترك شغل ران را غيراخلاقى و

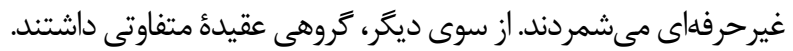

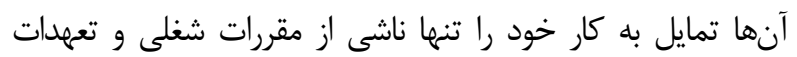

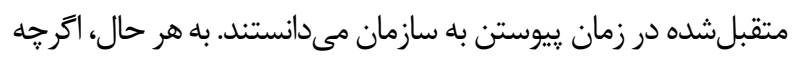
مىتوان كفت بيشتر كاركنان بنا به هر دليلى تمايل بالايى به كار دارند،

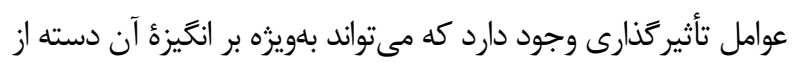

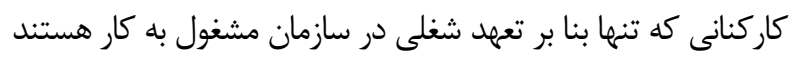

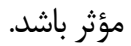
در اين مطالعه، مشاهده كرديم كه متغيرهاى دموكرافيك تأثير

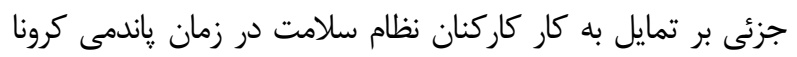

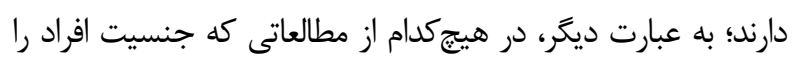

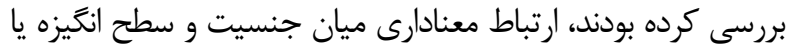
تمايل به كار مشاهده نشده بود. بهطور مشابهيى، ارتباط معنادارى ميان

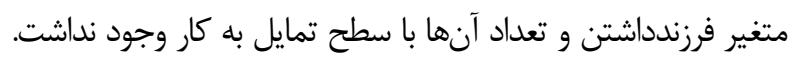

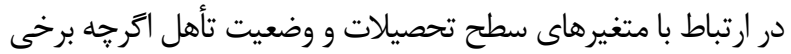

علاوه بر موارد فوق دستهاى ديكر از متغيرها وجود دارند كه تنها در يك مطالعه بررسى شدهاند. اين دسته از متغيرها شامل ميزان فاصله محل كار از منزل، شاغلبودن عضوى ديكر از

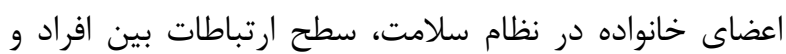
مديران در محيط كار، ديد مثبت فرد به شغل، ارتباط خوب إناب بيمار با يرستار، سطح كار گروهى در سازمان، نوع سازمان

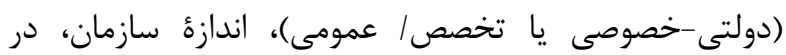
دسترس و مناسب بودن وسايل حفاظت فردى و سطح امكانات رفاهى هستند كه بهطور معنادارى با انكَيزٔ فرد به كار در شرايط

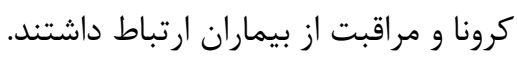

در اين مطالعأ مرور سيستماتيك، عوامل مؤثر بر انكَيزهٔ ماندن يا

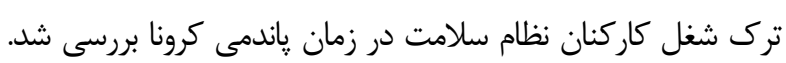

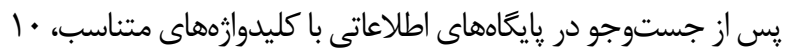
مقاله كه شرايط لازم را براساس معيارهاى ورود داشتند، بررسى شدائاس نتايج مطالعات حاكى از اين بود كه درصد بالايى از كاركنان نظام 
معنادارى با افزايش تمايل به خروج كار همراه بود كه در يك مطالعُ

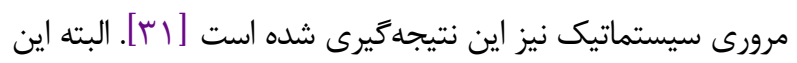

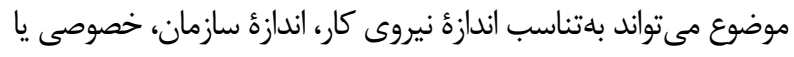

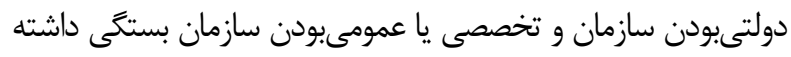

باشد.

نكرانى، استرس و ترس ناشى از مراقبت از افراد مبتلا به كرونا از

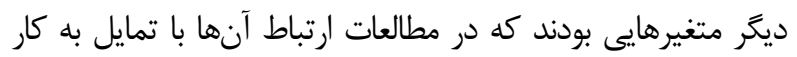

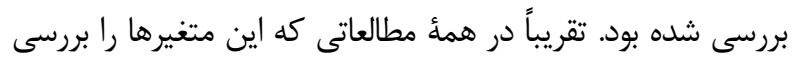

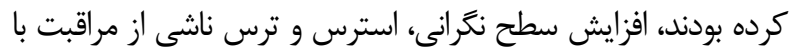

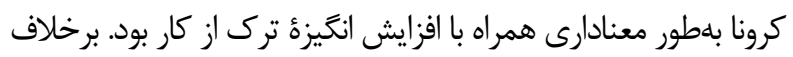

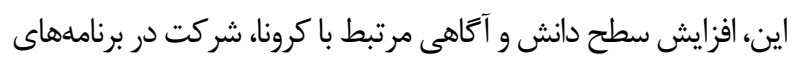

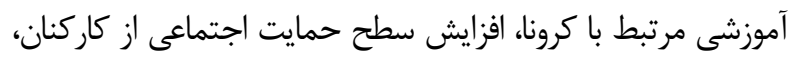

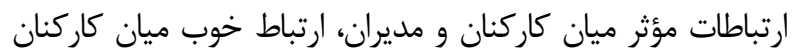

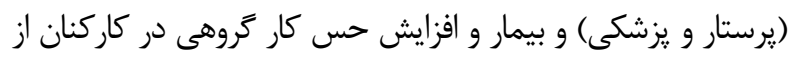

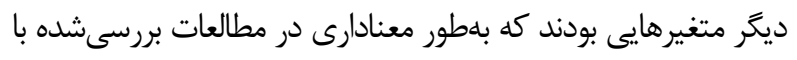

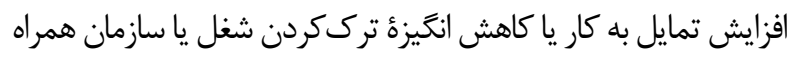

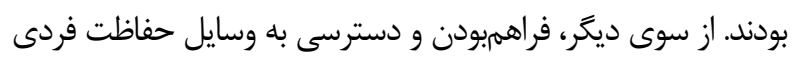

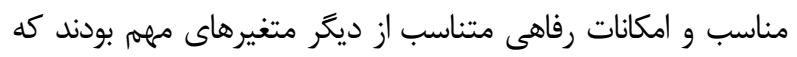

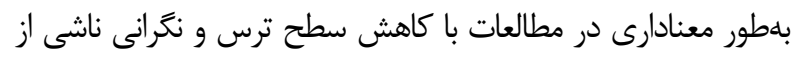

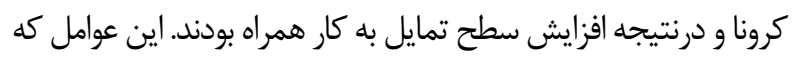

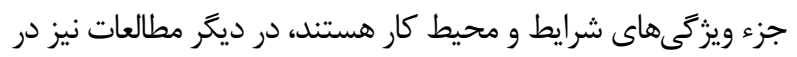

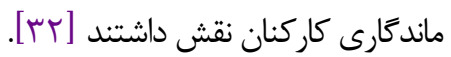

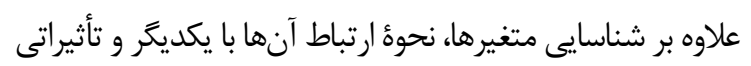

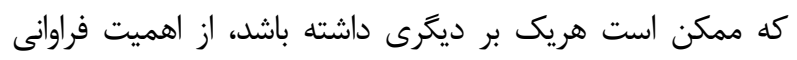

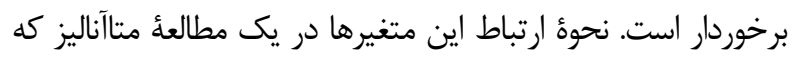

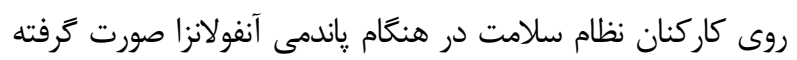

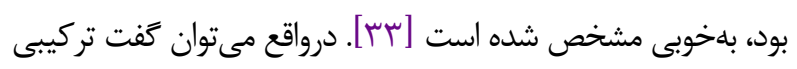

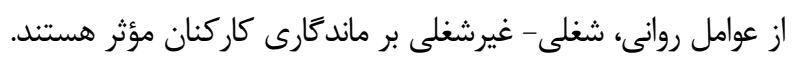

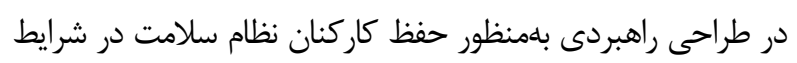

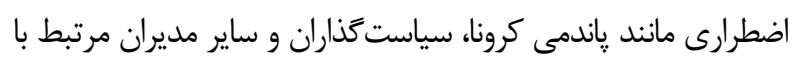
مديريت بحران علاومبر شناخت متغيرهاى تأثير كذار بايد بر اثر متقابل سنايل

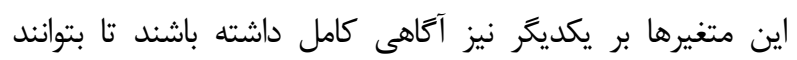

$$
\text { برنامههايى كارآدد راطراحى و اجرا كرد. }
$$

\section{نتيجه گَيرى}

در مطالعُ مرور سيستماتيك حاضر ارتباط عوامل شغلى - دارئ

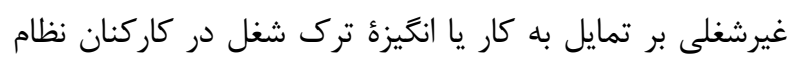
سلامت در زمان ياندمى كرونا بررسى شد. نتايج مطالعات نشان تركي
مطالعات ارتباط معنادارى را نشان داده بودند، در بيشتر مطالعاتى كه مهان

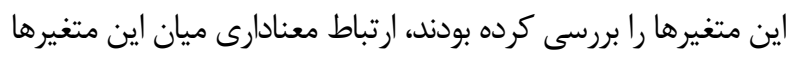

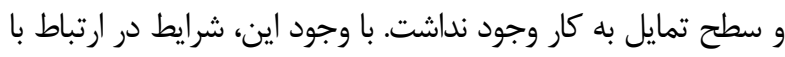

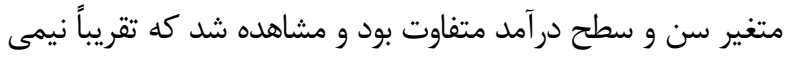

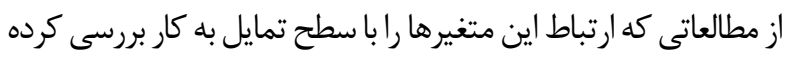

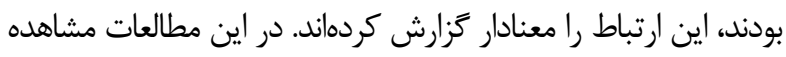

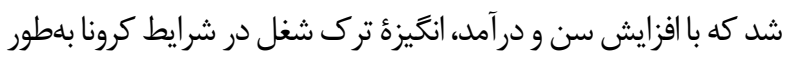

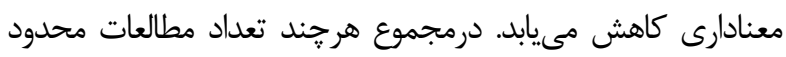

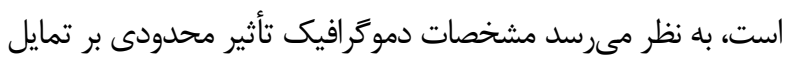
به كار كاركنان در زمان ياندمى كرونا دارد.

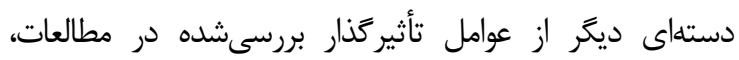

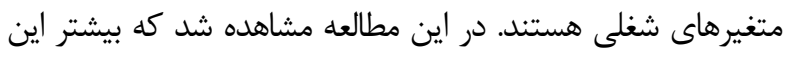

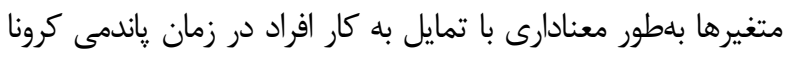

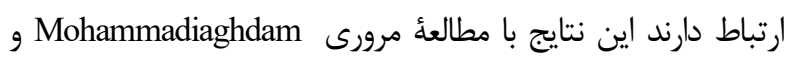

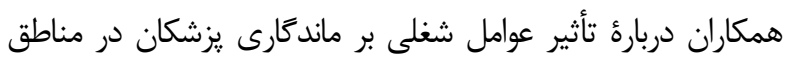

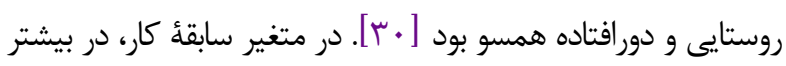

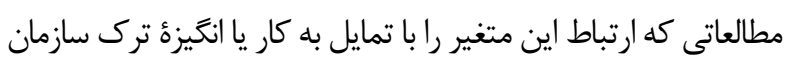

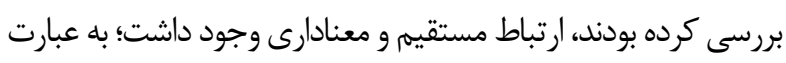

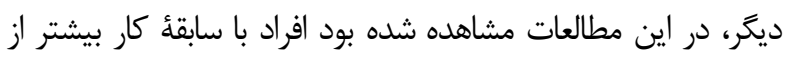

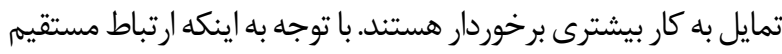

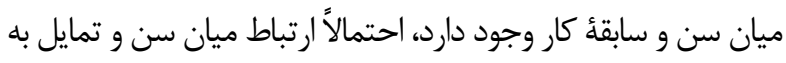

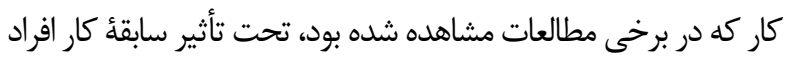

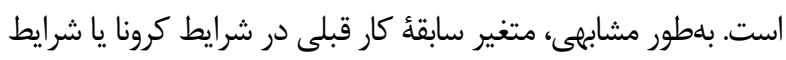

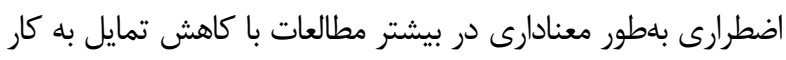

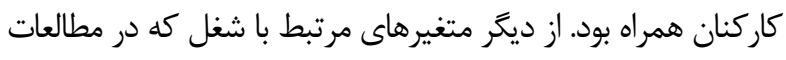

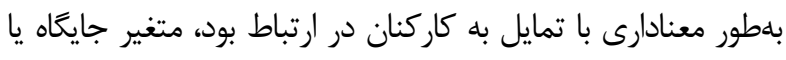

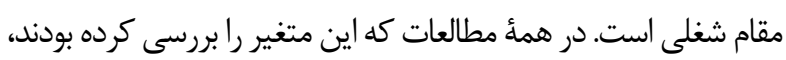

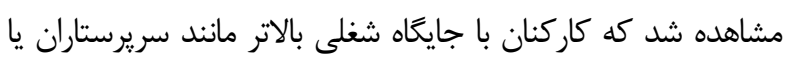

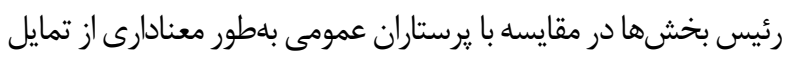

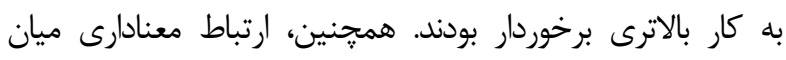

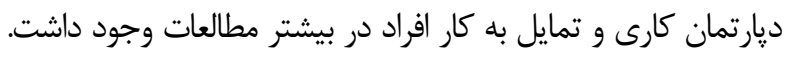

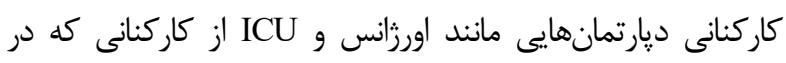

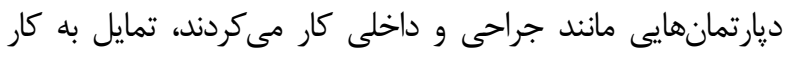

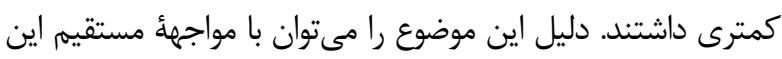

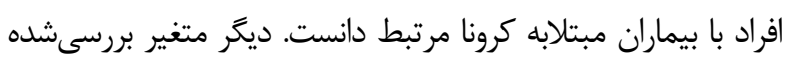

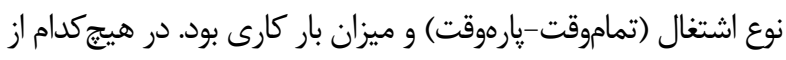

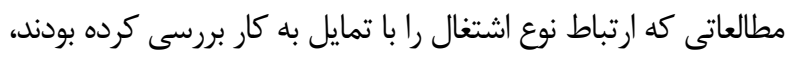

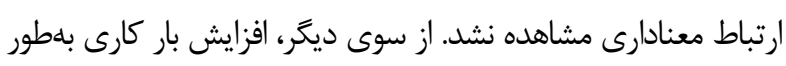




\section{بيشنهادها} براساس نتايج مطالعات بررسىشده مىتوان يِيشنهادهاى زير

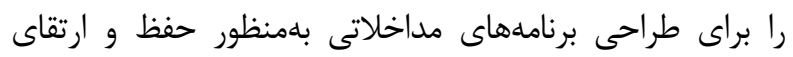
ماند

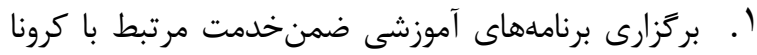
بdمنظور افزايش سطح آكاهى و نكرش كاركنان؛

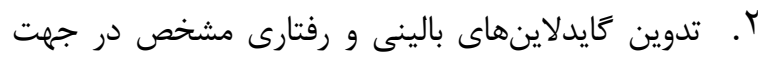
مديريت بيماران مبتلابه كرونا و ابلاغ آن به كاركنان؛

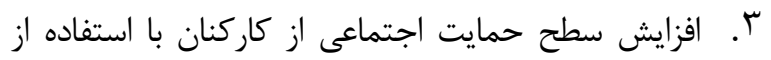
بستر شبكههاى اجتماعى و رسانههاى شنيدارى و ديدارى؛ P. طراحى مداخلات در جهت افزايش سطح انخيزه به كار كاركنان مانند افزايش سطح دستمزدها؛ ه. . ايجاد جوى دوستانه و مثبت در سازمان با افزايش سطح ماند ارتباطات و همكارى ميان كاركنان و مديران؛ 9. فراهمكردن وسايل حفاظت فردى با كيفيت و كميت مناسب براى استفاده كاركنان؛

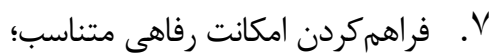

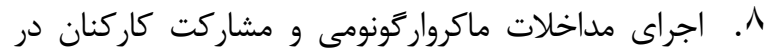
تصميهم

\section{تقدير و تشكر}

نويسند كردند، نهايت تقدير و تشكر را دارند.

\section{تعارض منافع}

بين نويسندگان هيجزَنه تعارضى در منافع وجود ندارد..

$$
\text { منابع مالى }
$$

\section{References}

1. Chen H, Guo J, Wang C, Luo F, Yu X, Zhang W, Li J, Zhao D, Xu D, Gong Q, Liao J. Clinical characteristics and intrauterine vertical transmission potential of COVID-19 infection in nine pregnant women: a retrospective review of medical records. lancet. 2020;395(10226):809-15. [DOI:10.1016/S01406736(20)30360-3]
مىدهد عوامل شغلى مانند سابقهُ كار، سابقهُ كار قبلى در شرايط اضطرارى يا كرونا، جايگاه شغلى، ديارتمان كارى، بار كارى، همكارى ميان كاركنان، ارتباطات مؤثر ميان كاركنان و مديران، دسترسى به وسايل حفاظت فردى و امكانات رفاهى متناسب مئب مى تواند بهطور معنادارى با تمايل به كار افراد همراه باشد. همجنين

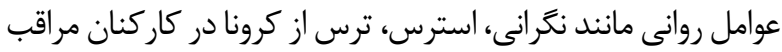
بيماران مبتلا به كرونا بهطور معنادارى با افزايش انخيزه ترك كردن شغل يا سازمان در ارتباط بود. با وجود اين، ارتباط معنادارى ميان

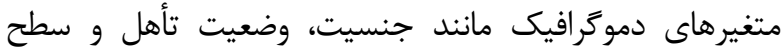
تحصيلات با سطح تمايل به كار وجود نداشت. با توجه به تعداد

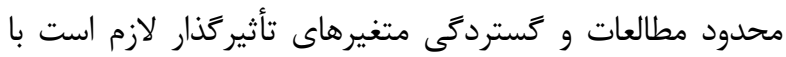
توجه به محدوديتهاى ذكرشده مطالعات بيشترى در اين باره

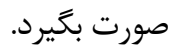

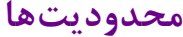

اين مطالعه همراه با محدوديتهايى بود كه لازم است هنگام تفسير نتايج مورد توجه قرار كيرد. در ابتدا بايد كفت مطالعات واردشده در اين مرور سيستماتيك از نوع توصيفى -تحليلى -مقطعى بودند. اين نوع از مطالعات محدوديت ذاتى در لوريني (Cross-Sectional) بررسى روابط علت-معلولى دارند. از طرفى ديخر، كيفيت مطالعات بررسىشده همراه با نكرانىهايى بود. در بيشتر مطالعات در بررسى ارتباط متغيرهاى شغلى - غيرشغلى با سطح تمايل به كار يا انخيزه

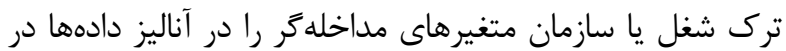
نظر گرفته نشده بودند. همجنين سنجش متغيرها بلهورت يرسشنامهاى و خوداظهارى بود كه روش توصيهشده براى سنجش

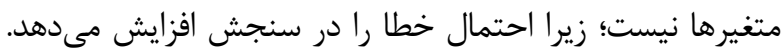
اين موضوع در يزوهش حاضر اهميت بيشترى دارد؛ زيرا بهدليل شرايط كرونا بيشتر يزوهشَّان از بستر وب و شبكههاى اجتماعى براى جمع آورى دادهها استفاده كرده بودند.
2. Reperant LA, Osterhaus AD. AIDS, Avian flu, SARS MERS, Ebola, Zika... what next? Vaccine. 2017;35(35):4470-4. [DOI:10.1016/j.vaccine.2017.04.082] [PMID] [PMCID] 
3. Yonge O, Rosychuk RJ, Bailey TM, Lake R, Marrie TJ. Willingness of university nursing students to volunteer during a pandemic. Public Health Nurs. 2010;27(2):174-80. [DOI:10.1111/j.15251446.2010.00839.x] [PMID]

4. Cheong SK, Wong TY, Lee HY, Fong YT, Tan BY, Koh GC, Chan KM, Chia SE, Koh D. Concerns and preparedness for an avian influenza pandemic: a comparison between community hospital and tertiary hospital healthcare workers. Ind. Health. 2007;45(5):653-61. [DOI: 10.2486/indhealth.45.653] [PMID]

5. Young A. The legal duty of care for nurses and other health professionals. J. Clin. Nurs. 2009 Nov;18(22):3071-8. [DOI:10.1111/j.13652702.2009.02855.x] [PMID]

6. Gold J. The COVID-19 crisis too few are talking about: health care workers' mental health. StatReports April. $2020 ; 3$.

7. Rangachari P, L Woods J. Preserving organizational resilience, patient safety, and staff retention during COVID-19 requires a holistic consideration of the psychological safety of healthcare workers. Int. J. Environ. Res. Public Health. 2020;17(12):4267. [DOI: 10.3390/ijerph17124267] [PMID] [PMCID]

8. Liu Z, Han B, Jiang R, Huang Y, Ma C, Wen J, Zhang T, Wang Y, Chen H, Ma Y. Mental health status of doctors and nurses during COVID-19 epidemic in China. Available at SSRN 3551329. 2020 Mar 4. [DOI:10.2139/ssrn.3551329]

9. Lai J, Ma S, Wang Y, Cai Z, Hu J, Wei N, Wu J, Du H, Chen T, Li R, Tan H. Factors associated with mental health outcomes among health care workers exposed to coronavirus disease 2019. JAMA network open. 2020;3(3):e203976-.

[DOI:10.1001/jamanetworkopen.2020.3976] [PMID] [PMCID]

10. Adams JG, Walls RM. Supporting the health care workforce during the COVID-19 global epidemic. Jama. 2020;323(15):1439-40. [DOI:10.1001/jama.2020.3972] [PMID]

11. Shanafelt T, Ripp J, Trockel M. Understanding and addressing sources of anxiety among health care professionals during the COVID-19 pandemic. Jama. 2020;323(21):2133-4.

[DOI:10.1001/jama.2020.5893] [PMID]

12. Li J, Li P, Chen J, Ruan L, Zeng Q, Gong Y. Intention to response, emergency preparedness and intention to leave among nurses during COVID-19. Nurs. 2020;7(6):1867-75. [DOI:10.1002/nop2.576] [PMCID]

13. Kim CJ, Yoo HR, Yoo MS, Kwon BE, Hwang KJ. Attitude, beliefs, and intentions to care for SARS patients among Korean clinical nurses: an application of theory of planned behavior. J Korean Acad Nurs. 2006;36(4):596-603.

[DOI:10.4040/jkan.2006.36.4.596] [PMID]
14. Ciezar-Andersen S, King-Shier K. Detriments of a selfsacrificing nursing culture on recruitment and retention: A qualitative descriptive study. Can. J. Nurs. Res. 2020:0844562120908747. [DOI: 10.1177/0844562120908747] [PMID]

15. Ives J, Greenfield S, Parry JM, Draper H, Gratus C, Petts JI, Sorell T, Wilson S. Healthcare workers' attitudes to working during pandemic influenza: a qualitative study. BMC public health. 2009;9(1):1-3. [DOI:10.1186/1471-2458-9-56] [PMID] [PMCID]

16. Kim YJ, Lee SY, Cho JH. A study on the job retention intention of nurses based on social support in the COVID-19 situation. Sustainability. 2020;12(18):7276. [DOI: 10.3390/su12187276]

17. Labrague LJ, de Los Santos JA. Fear of COVID-19, psychological distress, work satisfaction and turnover intention among frontline nurses. J. Nurs. Manag. 2021;29(3):395-403. [DOI:10.1111/jonm.13168] [PMID] [PMCID]

18. Lord H, Loveday C, Moxham L, Fernandez R. Effective communication is key to intensive care nurses' willingness to provide nursing care amidst the COVID19 pandemic. Dimens Crit Care Nurs. 2021;62:102946. [DOI:10.1016/j.iccn.2020.102946] [PMID] [PMCID]

19. Shi Y, Wang J, Yang Y, Wang Z, Wang G, Hashimoto $\mathrm{K}$, Zhang K, Liu H. Knowledge and attitudes of medical staff in Chinese psychiatric hospitals regarding COVID-19. Brain Behav. Immun. 2020;4:100064. [DOI:10.1016/i.bbih.2020.100064] [PMID] [PMCID]

20. Yáñez JA, Jahanshahi AA, Alvarez-Risco A, Li J, Zhang SX. Anxiety, distress, and turnover intention of healthcare workers in Peru by their distance to the epicenter during the COVID-19 crisis. Am. J. Trop. Med. Hyg. 2020;103(4):1614-20 [DOI:10.4269/ajtmh.20-0800] [PMID] [PMCID]

21. Moher D, Liberati A, Tetzlaff J, Altman DG, Group P. Preferred reporting items for systematic reviews and meta-analyses: the PRISMA statement. PLoS med. 2009;6(7):e1000097.

[DOI:10.1371/journal.pmed.1000097] [PMID] [PMCID]

22. Liberati A, Altman DG, Tetzlaff J, Mulrow C, Gøtzsche PC, Ioannidis JP, Clarke M, Devereaux PJ, Kleijnen J, Moher D. The PRISMA statement for reporting systematic reviews and meta-analyses of studies that evaluate health care interventions: explanation and elaboration. J. Clin. Epidemiol. 2009;62(10):e1-34. [DOI: 10.1016/j.jclinepi.2009.06.006] [PMID]

23. Hong QN, Fàbregues S, Bartlett G, Boardman F, Cargo M, Dagenais P, Gagnon MP, Griffiths F, Nicolau B, O'Cathain A, Rousseau MC. The Mixed Methods Appraisal Tool (MMAT) version 2018 for information professionals and researchers. Education for Information. 2018;34(4):285-91. [DOI:10.3233/EFI180221] 
24. Hong QN, Gonzalez-Reyes A, Pluye P. Improving the usefulness of a tool for appraising the quality of qualitative, quantitative and mixed methods studies, the Mixed Methods Appraisal Tool (MMAT). J Eval Clin Pract. 2018;24(3):459-67. [DOI:10.1111/jep.12884] [PMID]

25. Hong QN, Pluye $P$, Fàbregues $S$, Bartlett G, Boardman F, Cargo M, Dagenais P, Gagnon MP, Griffiths F, Nicolau B, O'Cathain A. Improving the content validity of the mixed methods appraisal tool: a modified eDelphi study. J. Clin. Epidemiol. 2019;111:49-59. [DOI: 10.1016/j.jclinepi.2019.03.008] [PMID]

26. Wu B, Zhao Y, Xu D, Wang Y, Niu N, Zhang M, Zhi $\mathrm{X}$, Zhu P, Meng A. Factors associated with nurses' willingness to participate in care of patients with COVID-19: A survey in China. J. Nurs. Manag. 2020;28(7):1704-12. [DOI:10.1111/jonm.13126] [PMID] [PMCID]

27. Irshad M, Khattak SA, Hassan MM, Majeed M, Bashir S. How perceived threat of COVID-19 causes turnover intention among Pakistani nurses: A moderation and mediation analysis. Int J Ment Health Nurs. 2020.

28. Nashwan AJ, Abujaber AA, Mohamed AS, Villar RC, Al-Jabry MM. Nurses' willingness to work with
COVID-19 patients: The role of knowledge and attitude. $\quad$ Nurs. 2021;8(2):695-701. [DOI: 10.1002/nop2.674] [PMID] [PMCID]

29. Gan X, Shi Z, Chair SY, Cao X, Wang Q. Willingness of Chinese nurses to practice in Hubei combating the coronavirus disease 2019 epidemic: A cross-sectional study. J Adv Nurs. 2020;76(8):2137-50. [DOI:10.1111/jan.14434] [PMID] [PMCID]

30. Mohammadiaghdam N, Doshmangir L, Babaie J, Khabiri R, Ponnet K. Determining factors in the retention of physicians in rural and underdeveloped areas: a systematic review. BMC Fam. Pract. 2020;21(1):1-23. [DOI:10.1186/s12875-020-012797] [PMID] [PMCID]

31. Goins RE. Systematic Review of Retention of DirectCare Workers in Long-term Care Facilities: Walden University; 2015.

32. Mbemba GI, Gagnon MP, Hamelin-Brabant L. Factors influencing recruitment and retention of healthcare workers in rural and remote areas in developed and developing countries: an overview. East Afr. J. Public Health. 2016;7(2). [DOI:10.4081/jphia.2016.565] [PMID] [PMCID] 